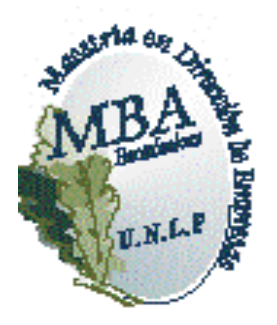

Universidad Nacional de La Plata

Facultad de Ciencias Económicas

MBA - Maestría en Dirección de Empresas

\title{
Fundamentos y pautas para una Gestión Ética y Socialmente Responsable
} (GESR)

Aplicación en empresas del sector farmacéutico

Trabajo final para optar al título de Magíster

Autor: Ing. José Augusto Fantasía

Director: Dr. Juan José Gilli

La Plata

Agosto 2011 


\section{Índice}

Resumen __ 1

1. Planteo del Problema___ 2

2. Objetivos de la Investigación___ 3

3. Evaluación del Problema ___ 4

3.1 Fundamentos de la Gestión Ética y Socialmente Responsable (GESR)___ 4

3.2 Pautas para la Gestión Ética y Socialmente Responsable (GESR) __ 6

4. Alcance de la Investigación __ 7

5. Marco Teórico de Referencia___ 8

5.1 Evolución de las ideas sobre RSE___ 8

5.2 Evolución cronológica en materia normativa de RSE para el sector farmacéutico ___ 13

5.2.1 Normas sobre "seguridad, calidad y eficacia" específicas de la Industria Farmacéutica

5.2.2 Las Normas de RSE en la Industria Farmacéutica 15

5.2.3 Acciones y programas de Resposabilidad Social Empresaria (RSE) específicos para las empresas farmacéuticas nacionales e internacionales _ـ 16

6. Metodología de la Investigación____ 33

6.1. Población y Muestra ___ 33

6.2. Tipo de Investigación __ 34

6.3. Técnicas de Recolección de Datos __ 34

6.4. Técnicas de Análisis___ 35

7. Resultados de la Investigación ___ 35

7.1 Organización de "RSE" __ 36

7.2 Gestión Ética y Socialmente Responsable (GESR) __ 37

8. Conclusiones___ 44

9. Recomendaciones _ـ 46

10. Bibliografía__ 50

11. Glosario de Términos___ 53

12. Referencias y Anexos___ 55

12.1 Directrices de RSE _ 55

12.2 Informes sociales

12.3 Acreditaciones y certificaciones _ 61

12.4 Principales programas y acciones en materia de RSE de las empresas estudiadas__ 69

12.5 Cuestionario dirigido a los responsables de RSE __ 73 


\section{Resumen}

Aunque los temas de ética y de responsabilidad social tienen un cierto carácter intangible, no pueden dejarse a la buena voluntad de las personas; pueden y deben gestionarse.

Nace de esta manera el concepto de Gestión Ética y Socialmente Responsable (GESR), actualmente voluntaria, que requiere a la organización un compromiso que demuestre su integración en la estrategia y procesos; el impulso del diálogo y el conocimiento de las expectativas de los grupos de interés (entidades o individuos a los que pueden afectar de manera significativa las actividades, productos y/o servicios de la organización) y el fomento de la transparencia y la comunicación (publicación de la triple cuenta de resultados: económico, social y ambiental).

Por cuestiones de naturaleza y de condiciones del mercado, en este trabajo se analizan las percepciones y acciones de cinco empresas del Sector Farmacéutico: Bagó, Bayer, Novartis, Roche y Roemmers, para evidenciar el compromiso que este Sector tiene con la GESR. 
"Responder a las exigencias morales más profundas de la persona tiene también importantes efectos beneficiosos en el plano económico. En efecto, la economía tiene necesidad de la ética para su correcto funcionamiento; no de una ética cualquiera, sino de una ética amiga de la persona. Hoy se habla mucho de ética en el campo económico, bancario y empresarial.

Surgen centros de estudio y programas formativos de business ethics; se difunde en el mundo desarrollado el sistema de certificaciones éticas, siguiendo la línea del movimiento de ideas nacido en torno a la responsabilidad social de la empresa" CARTA ENCÍCLICA CARITAS IN VERITATE (latín: La caridad en la verdad) DEL SUMO PONTÍFICE BENEDICTO XVI 29 de junio de 2009

\section{Planteo del Problema}

"La necesidad de que las empresas tengan en cuenta criterios de ética y de responsabilidad social en sus actuaciones diarias parece estar ampliamente aceptado. Los factores que han contribuido a esta nueva forma de entender la actividad empresarial son muchos: las demandas sociales, que piden a las empresas que tengan en cuenta otros aspectos al valorar sus acciones; el impacto de las nuevas tecnologías, que provocan una mayor transparencia en la información; el debate en el mundo académico sobre la naturaleza y el fin de la empresa; las propuestas de los organismos internaciones y de la sociedad civil; la propia reflexión de la comunidad empresarial sobre su papel en el desarrollo de la sociedad.

Sin embargo, queda mucho por hacer para pasar de las palabras a los hechos, y para que la sensibilización sobre estos temas se transforme, de verdad, en acciones concretas en las empresas. El debate sobre la responsabilidad social se mueve, en efecto, entre estos dos ámbitos: el debate conceptual y la fundamentación teórica, y la aplicación práctica. 
Pero es ésta la que de verdad importa, si lo que queremos es cambiar conductas.

El mensaje que es preciso transmitir es, por tanto, que los temas de ética y de responsabilidad social tienen un cierto carácter intangible, pero que los intangibles pueden gestionarse. La ética y la responsabilidad social no pueden dejarse a la buena voluntad de las personas; pueden y deben gestionarse. Hay herramientas y procesos de gestión que permiten dotar a las empresas de medios para asegurarse que los criterios sociales, medioambientales y éticos son considerados en las decisiones diarias de sus empleados del mismo modo que lo son los aspectos económicos" (Fontrodona Felip, 2005).

En particular, la aplicación práctica de la ética y responsabilidad social es un problema que actualmente subyace en la estrategia empresarial del sector farmacéutico por dos motivos:

1. Es una demanda natural al sector debido a su propia esencia y su actividad principal relacionada con la salud y al consecuente impacto en la calidad de vida de la sociedad.

2. Las empresas del sector farmacéutico, junto con las nuevas normas farmacéuticas nacionales e internacionales y otras barreras de ingreso al mercado global, se ven inducidas a desarrollar herramientas y procesos de gestión ética y socialmente responsable, de manera voluntaria, con el fin de asegurarse un nicho en el mercado, donde la responsabilidad sobre el producto es el factor clave determinante del éxito (Castner et al., 2007).

Resulta oportuno estudiar, entonces, las actividades y las prácticas en GESR que realiza la Industria Farmacéutica y evidenciar el compromiso que tiene con la GESR.

\section{Objetivos de la Investigación}

- Describir teóricamente los fundamentos y pautas para una Gestión Ética y Socialmente Responsable (GESR). 
- Especificar cuáles son las acciones y programas de Resposabilidad Social Empresaria (RSE) para las empresas farmacéuticas nacionales e internacionales.

- Identificar los modos de gestión interna de RSE en términos de la estructura de la organización en empresas de farmacéuticas, de capital nacional o multinacional, que tienen filiales en Argentina.

- Relevar acciones y programas de RSE en estas empresas farmacéuticas para verificar el grado en que la GESR forma parte integral de la empresa y el compromiso con la misma.

- Detectar las necesidades para implantar un Sistema de GESR con el fin de que estas empresas farmacéuticas puedan demostrar su transparencia, integridad y sostenibilidad, entendida esta última en su triple vertiente: económica, ambiental y social.

\section{Evaluación del Problema}

\subsection{Fundamentos de la Gestión Ética y Socialmente Responsable} (GESR)

Tanto las grandes compañías como las pequeñas y medianas empresas, empiezan a integrar la Responsabilidad Social Empresaria en su gestión como una herramienta estratégica adicional para garantizar su futuro.

Existen, pues, innumerables factores de carácter estratégico que motivan dicha iniciativa:

\section{1) Factores internos}

La cultura empresarial es uno de los principales vehículos de comunicación interna y un terreno abonado sobre el que establecer ventajas competitivas.

El clima laboral repercute en varias palancas que son clave para la productividad de las compañías: 
- Motivación

- Reducción del absentismo

- Captación y retención de talento

\section{2) Factores externos}

- Credibilidad en el equipo gestor

- Reducción del riesgo operativo

- Disminución de la incertidumbre

- Creación de barreras de entrada: una marca sólida dificulta la entrada de competidores a un mercado. La dotación a la marca de atributos emocionales favorece el establecimiento de vínculos entre el comprador y el producto, contribuyendo a la diferenciación.

- Orientación de mercado: un mayor diálogo y cercanía con los grupos de interés o stakeholders (clientes, proveedores, personas que integran la organización, inversores, etc.) permite una mayor anticipación a los cambios en el mercado.

- Relaciones con las administraciones públicas: una mayor cooperación con las administraciones reduce el riesgo de infracciónsanción, y aporta solidez al entorno regulatorio.

- Incremento de la satisfacción del cliente: en un entorno competitivo la calidad intrínseca del producto deja de ser el criterio de diferenciación, compitiendo por servicio y percepción.

- Mejora de las condiciones económicas de la comunidad: genera negocio a largo plazo.

- Mejoras sociales en la comunidad: el acceso a una mejor educación y sanidad, incrementa la calidad de vida y la productividad de la población.

Teniendo en cuenta dichos factores, la Gestión Ética y Socialmente Responsable (GESR) se define como "la integración voluntaria en el gobierno, gestión, estrategia, políticas y procedimientos de las organizaciones, de las preocupaciones sociales, éticas, laborales, medioambientales y de respeto a los derechos humanos que surgen de la relación y el diálogo transparentes con sus grupos de interés, 
responsabilizándose así de las consecuencias y los impactos que se derivan de sus acciones" (Forética, 2008).

El sector farmacéutico tiene un papel pionero en la GESR. En este sentido cabe señalar que la industria farmacéutica ha sido innovadora en cuanto a aportar valor a la humanidad a través de su investigación. La calidad y eficacia de sus productos ha mejorado $y$ alargado considerablemente la vida de los pacientes. Asimismo ha sido pionera en la implementación de sistemas de calidad y de protección del medioambiente, y en políticas de recursos humanos que integran la calidad de trabajo, beneficios, igualdad de oportunidades, la gestión de la diversidad, valores éticos y transparentes (García Martinez, 2006).

Así, la industria farmacéutica constantemente promulga la materialización de estándares éticos en diversas acciones de la empresa.

\subsection{Pautas para la Gestión Ética y Socialmente Responsable (GESR)}

Anteriormente se afirmó que la GESR es voluntaria. No obstante, requiere un compromiso que demuestre al menos tres elementos esenciales. En primer lugar, su integración en la estrategia y procesos de la organización. En segundo lugar, el impulso del diálogo y el conocimiento de las expectativas de los grupos de interés. Por último, el fomento de la transparencia y la comunicación donde la publicación de la triple cuenta de resultados (económico, social y ambiental) se ha convertido en una práctica común en las grandes empresas.

Para alcanzar dicho objetivo, se recomienda que la Alta Dirección disponga de una herramienta de gestión sistemática que interactúe dentro del modelo de gestión empresarial de la organización y, por tanto, sea compatible e integrable con otros sistemas de gestión ya implantados, como el de calidad, medioambiente, prevención de riesgos laborales, entre otros. Además debe ser verificable. 


\section{Alcance de la Investigación}

Según el ranking de las 100 compañías socialmente responsables mejor percibidas, publicado por la Revista Mercado en su edición de noviembre 2009 , entre las pocas compañías que ganaron imagen del año 2008 al 2009, se destacan dos farmacéuticas: Roche y Bayer, un sector que, además, tiene a Labatorios Bagó S.A. en el top ten.

Observando el resto del ranking, próximo al listado de las 10 primeras se encuentra Roemmers y sobre el final a Novartis Argentina. Las posiciones son las siguientes:

4 Roche

7 Labatorios Bagó S.A.

9 Bayer

14 Roemmers

90 Novartis Argentina

En la edición reciente de noviembre 2010 de la Revista Mercado, dichas compañías se mantuvieron dentro del ranking de las 100 empresas socialmente responsables mejor percibidas:

4 Roche

8 Labatorios Bagó S.A.

11 Bayer

33 Roemmers

79 Novartis Argentina

Por otro lado la Revista Apertura en su edición 208, de marzo de 2011, publicó el ranking las 100 mejores empresas en imagen de la Argentina.

Dentro de los Laboratorios e industrias químicas, los arriba mencionados fueron también los elegidos en primer lugar por los empresarios, consultores y peridiodistas entrevistados por la revista.

1 Laboratorios Bagó (100 puntos)

2 Bayer (55,170 puntos)

3 Roemmers (37,960 puntos)

5 Roche $(26,416)$

6 Novartis $(24,858$ puntos) 
El alcance de la investigación se limitará al estudio de estas cinco compañías.

\section{Marco Teórico de Referencia}

\subsection{Evolución de las ideas sobre RSE}

\section{Los cincuenta}

El concepto de responsabilidad social de la empresa se originó en los años cincuenta, ligado al rápido incremento de tamaño y poder de las empresas americanas. Y el tema continuó figurando prominentemente en el debate público durante los años sesenta y setenta, mientras Estados Unidos afrontaba problemas sociales urgentes, como la pobreza, el paro, las relaciones entre razas, la degradación urbana y la contaminación. La responsabilidad social de la empresa se convirtió en clamor compartido por diversos grupos que exigían cambios en los negocios americanos (Boatright, 1993). Previo a esta etapa se puede encontrar una raíz de los planteamientos propios de la responsabilidad social de la empresa en los pasos que se empiezan a dar a principios de los años veinte, hacia lo que podríamos llamar la filantropía empresarial. Este concepto encontraba soporte en dos principios: el de caridad y el de administración. El principio de caridad instaba a las empresas a que dieran voluntariamente ayuda a los grupos sociales desafortunados o necesitados, mientras que el principio de administración las instaba a que se hicieran cargo del interés público, lo que significaba que habrían de actuar en interés de todos los miembros de la sociedad que estuvieran afectados por las operaciones empresariales (Lozano, 1999).

Otro sector de la doctrina, encabezado por Sheldon (1923) y continuado luego por Friedman (1970), consideraban a la empresa como una institución meramente económica que debía circunscribir sus responsabilidades a lo económico, respetando las normas legales y la ética de la sociedad. Entendían que las responsabilidades sociales de la empresa serían absorvidas por el mercado a través de sus libres 
mecanismos. Friedman afirmaba que la obligación moral de los directivos de la empresa es generar beneficios para los accionistas y que, por lo tanto, usar sus recursos para satisfacer otros fines sería un "robo" a los accionistas.

Hay quienes afirman que el concepto moderno de RSE comienza en la década del cincuenta con la definición propuesta por Bowen (1953), quien planteó la RSE como la obligación del directivo de empresa de perseguir políticas, tomar decisiones y seguir líneas de acción deseables, para los objetivos y los valores de la sociedad. La definición de Bowen tiene especial relevancia debido a que en aquel entonces no se conocía más que la filantropía empresaria.

\section{Los sesenta}

En la década del sesenta, Davis (1960) hizo su aporte diciendo que la responsabilidad social es un término aplicable a aquellas decisiones y acciones adoptadas por los empresarios debidas a motivaciones que van más allá del interés económico o técnico. Davis formuló la "Ley de Oro de la Responsabilidad", que sostiene que la responsabilidad social de los empresarios debería ser acorde al poder social de las empresas.

Durante la misma década, Frederick (1960) planteó que los medios de producción debían ser utilizados de manera tal que fortaleciesen el bienestar económico-social, sosteniendo que la responsabilidad social es el deber de toda persona de tener en cuenta el impacto de sus actos en todo el sistema social, lo cual implica la necesidad de mirar más allá de lo estrictamente económico o productivo de la empresa, considerando el sistema social en su conjunto.

\section{Los setenta}

Durante los setenta tuvo un papel muy importante la declaración del Comitee for Economic Development de 1971, en la que se consideraba la responsabilidad social de la empresa no tan sólo un concepto de gestión o una cuestión que afectaba a cada empresa considerada individualmente, sino que subrayaba el papel social de la empresa como una herramienta importante para el progreso social en una sociedad pluralista. $Y$ por esta 
razón nació un planteo en orden a qué habrían de hacer las empresas con relación a diez problemas sociales específicos: el crecimiento económico y la eficiencia, la educación, la ocupación y la formación, los derechos civiles y la igualdad de oportunidades, el desarrollo urbano, la contaminación, el conservacionismo y la ecología, la cultura y las artes, la atención médica y las acciones del gobierno.

\section{Los ochenta}

Peter Drucker (1984) planteó que la empresa debe convertir su RSE en una oportunidad de negocios integrada a las necesidades de la sociedad con la actividad empresaria, convirtiendo problemas sociales en oportunidades de negocios, en capacidad de producción, en trabajos bien remunerados y en riqueza.

Durante el mismo año, Freeman (1984) propuso la teoría del stakeholder al flujo de literatura de administración de empresas. La teoría presenta a las empresas como un sistema relacionado con la sociedad, no de un modo abstracto sino a través de un grupo de stakeholders representativos, en una relación de doble sentido. Los stakeholders son cualquier individuo o grupo que puede afectar o es afectado por el logro de los objetivos de la empresa. Esta visión hace énfasis en que los intereses de todos los stakeholders deberían estar incorporados a la empresa. Los grupos de stakeholders primarios son aquellos sin cuya continua participación la empresa no puede sobrevivir: los accionistas, inversores, empleados, clientes y proveedores. El grupo de stakeholders secundarios es el que influye o es influido por la empresa, pero que no participa en sus operaciones ni es esencial para su supervivencia; los medios y una amplia gama de grupos de interés son considerados stakeholders secundarios. Estos tienen la capacidad de movilizar la opinión pública a favor o en contra de una empresa, pudiendo dañarla de manera significativa. En tanto, el grupo de los stakeholders públicos está formado por los gobiernos y comunidades que proporcionan la infraestructura y los mercados, cuyas leyes y regulaciones deben ser obedecidas y a quienes se le deben pagar impuestos y otras obligaciones. Las últimas dos décadas son testigos de los esfuerzos puestos en incluir el medio ambiente como un legítimo 
stakeholder de la empresa, contribuyendo a la idea de desarrollo sustentable o sostenible.

El desarrollo sustentable o sostenible de la empresa se centra en dirigir, monitorear y evaluar las actividades comerciales para asegurar que no tengan un efecto perjudicial en el medio ambiente natural y biofísico, a corto o largo plazo.

\section{Los noventa hasta la actualidad}

En esos años surgió la noción de Corporate Citizenship o Ciudadanía Empresarial. El término es relativamente antiguo ya que la expresión aparece en Estados Unidos en la década de los ochenta, o quizá antes, sobre todo en la práctica empresarial para designar acciones filantrópicas empresariales para contribuir a solucionar determinadas necesidades sociales de la comunidad donde opera la empresa. "La empresa - se afirmaba - ha de ser una buena ciudadana» $y$, si hay ciudadanos que se preocupan y ayudan a resolver problemas o necesidades sociales, las empresas, sobre todo las grandes, con sus inmensos recursos, no pueden ser menos.

La idea de que las empresas tienen que preocuparse por las comunidades que las acogen, más allá del pago de impuestos, se extendió progresivamente con las protestas antiglobalización a finales del siglo pasado y principios del actual. En gran medida, contribuyó a ello una declaración firmada por 34 directores ejecutivos de las mayores empresas del mundo dentro del World Economic Forum de 2002, celebrado ese año en Nueva York en lugar de Davos (Suiza), donde habitualmente tiene lugar. En esta declaración del World Economic Forum se afirma que la ciudadanía empresarial se refiere a la contribución que una compañía hace a la sociedad a través de sus actividades empresariales nucleares, su inversión social y programas filantrópicos y su implicación en políticas públicas (Melé, 2007).

La RSE entonces, según esta teoría, es un modelo de gestión que incluye el conjunto de responsabilidades económicas, sociales y medioambientales que tienen las organizaciones con su entorno, con el 
requerimiento de una mayor transparencia, sin desproteger los intereses de los stakeholders.

El nombre de ciudadanía empresarial en algunos lugares resulta más atractivo que el de responsabilidad social. Da idea de que la empresa es parte activa de la sociedad y no sólo una entidad con responsabilidades exigidas por otros. Aquí, al igual que el modelo de los stakeholders, la empresa no es considerada únicamente como un agente económico.

En la misma década del noventa, Donaldson (1999) fundamenta la RSE desde la "teoría del contrato social". Esta teoría se sustenta en la noción de que las empresas no podrían existir sin la cooperación y el compromiso de la sociedad; si la sociedad rechaza el funcionamiento del sector empresario, éste se verá obligado a transformarse. ¿Cómo se justifica la aplicación del contrato social al ámbito empresario? La empresa toma sus empleados de la sociedad, vende sus productos o servicios a la sociedad y es la sociedad quien le otorga o lo quita cierto status a la empresa. Todo esto parece justificar la existencia de un contrato implícito entre la empresa y la sociedad que implica la existencia de una relación entre las empresas y la sociedad. Parte del contrato social se refleja en leyes y regulaciones, así como en las costumbres y valores socialmente aceptados que influyen en la actividad empresaria.

En conclusión, en la teorización reciente de RSE aparecen dos elementos básicos o esenciales: “1) una cosmovisión implícita o explícita que fundamenta normativamente cómo ha de ser el comportamiento empresario en la sociedad; y 2) una invitación al cambio de comportamiento empresarial, con acciones que vayan más allá de la ley...La invitación a las empresas consiste en que éstas deben considerar un espectro más amplio de obligaciones que las que tienen con sus propietarios o accionistas. Estas obligaciones con la sociedad van más allá de los límites tradicionales de acción y responsabilidad y suponen una visión ampliada del trabajo y la empresa, que debe satisfacer o exceder las expectativas éticas, legales, comerciales y públicas que la sociedad deposita en ellos. La invitación consiste también en que la empresa «se haga cargo» del modo en que ha elegido hacer negocios" (Precioza, 2005). 


\subsection{Evolución cronológica en materia normativa de RSE para el sector} farmacéutico

\subsubsection{Normas sobre "seguridad, calidad y eficacia" específicas de la}

\section{Industria Farmacéutica}

A comienzos del siglo $\mathrm{XX}$, dada la creciente preocupación por parte de las autoridades sanitarias y de los consumidores en general con relación a los medicamentos surge, en el ámbito mundial, la necesidad de fiscalizar la elaboración y control de los mismos. Uno de los primeros avances hacia este objetivo fue la creación de la Food and Drug Administration (FDA) en los Estados Unidos en 1906.

El propósito principal de este tipo de Agencias es garantizar la eficacia (cumplimiento del objetivo terapéutico, nutricional o diagnóstico), seguridad (alto coeficiente beneficio/riesgo) y calidad (tanto de diseño como de aptitud al uso) de los medicamentos.

A comienzos de los años '60, los graves efectos que provocó la talidomida en Inglaterra y Alemania al ser prescrita como sedante a embarazadas -produciendo defectos de nacimiento en muchos de sus hijos-, significó que la FDA elevara el nivel de exigencia de sus controles, lo que fue especificado en la enmienda Kefauver Harris de 1962. Desde entonces, para que se aprobara la comercialización de nuevas drogas, además de comprobar la seguridad, fue necesario acreditar su eficacia.

Este estándar buscaba que la droga fuera pura, segura y funcionara tal como se la promocionaba, normativa que se amplió a los medicamentos sin receta en 1972 y fue aplicada a todos los productos de la industria farmacéutica estadounidense 10 años más tarde.

La reforma Kefauver Harris estableció que todos los fabricantes de medicamentos debían registrarse ante la FDA. Por su parte, el organismo efectuaría una inspección a todos los productos de estas empresas cada dos años. Con el objetivo de dar a conocer dichas exigencias, la FDA publicó en 1963 un reglamento que establecía los requerimientos específicos para la elaboración de fármacos, normas que son consideradas 
como el punto de partida de las Buenas Prácticas de Fabricación (BPF) o, en inglés, Good Manufacturing Practices (GMP).

En un comienzo, las reglas tenían sólo carácter de recomendación, constituyendo una suerte de código de ética profesional farmacéutica. Sin embargo, en 1973 la Corte Suprema de Estados Unidos decretó que toda normativa adoptada por la FDA, debería ser considerada con carácter y fuerza legal, incluyendo las GMP. Desde entonces, para las autoridades de ese país todo medicamento que no se fabrique de acuerdo a estas normas, debe considerarse como un fármaco posiblemente adulterado.

Con el objetivo de mantener su vigencia, las Normas GMP han sido actualizadas periódicamente. En 1967 la Organización Mundial de la Salud (OMS) solicitó a un grupo de expertos elaborar un borrador que fuera el sustento de la regulación, documento que se hizo efectivo dos años más tarde como parte integral del "Sistema de Certificación de la Calidad de los Productos Farmacéuticos Objeto de Comercio Internacional". En 1992 la OMS actualizó las normas y les imprimió mayores exigencias, considerando otros reglamentos internacionales, como por ejemplo las normas ISO. Este borrador dio origen a las Normas GMP de la OMS, aprobadas por resolución en 1994. La última versión de las mismas es del 2003.

En el año 2004, en Argentina, la Administración Nacional de Medicamentos, Alimentos y Tecnología Médica (ANMAT) emitió la Disposición 2819/2004 donde se aprueban los lineamientos generales de Buenas Prácticas de Fabricación (BPF) para Elaboradores, Importadores/Exportadores de Medicamentos. En la Disposición mencionada se establece que mediante la Disposición (ANMAT) n $n^{\circ}$ 853/99 se adoptaron las recomendaciones sobre Buenas Prácticas de Fabricación para la Industria Farmacéutica aprobadas por la Asamblea Mundial de la Salud en mayo de 1992. Asimismo que como consecuencia de los avances tecnológicos resulta necesario adoptar las Recomendaciones sobre Buenas Prácticas de Fabricación y Control de 2003, aprobadas por la Asamblea Mundial de la Salud e informes de la PIC'S -Pharmaceutical Inspection Corporation Scheme-: PE 009-1 e ICH - International Conference on Harmonisation - Guía de GMP - Q7A. 


\subsubsection{Las Normas de RSE en la Industria Farmacéutica}

A pesar de la existencia de los requisitos reguladores nacionales e internacionales y de requerimientos específicos para la elaboración de fármacos (GMP), inevitablemente muchas empresas farmacéuticas se han enfrentado a problemas de responsabilidad social que se derivan de dar lugar a demandas judiciales alegando efectos secundarios adversos de los medicamentos. Por ejemplo, una de las compañías farmacéuticas más importantes del mundo, Merck, ha sido el blanco de más de 22.000 demandas de responsabilidad civil en los Estados Unidos. En una gran mayoría de estos casos se trataba del analgésico Vioxx, que fue retirado del mercado en septiembre de 2004 a causa de eventos cardiovasculares adversos derivados de su uso.

Por tanto la exigencia de mecanismos de monitoreo de la industria en referencia a cuestiones de responsabilidad social se ha transformado en una de las condiciones impuestas por el mercado global para las empresas del sector farmacéutico. Esta situación ha inducido a que varias de las más importantes empresas multinacionales crearan normas propias voluntarias y desarrollen la idea de RSE.

Desde finales de los años noventa, las multinacionales han comenzado a elaborar informes que incluyeron de una forma u otra, vertientes sociales y medioambientales. $\mathrm{Y}$, como es lógico, en esa tarea de informar empezaron a encontrarse con el problema de cómo medir las acciones de RSE y sus resultados, de forma que la información fuese coherente, completa y ordenada. Paralelamente, organizaciones de la sociedad civil y foros de grupos de interés desarrollaron recomendaciones o normas para la elaboración de estos informes (Lena Strandberg, 2010), las cuales están basadas en las teorías de RSE sobre los stakeholders, desarrollo sustentabe y ciudadanía empresarial.

Adicionalmente, los Laboratorios nacionales vinculados a las multinacionales, por ser proveedores de las mismas (procesos de tercerización), van siendo inducidos a aplicar normas de RSE mediante las auditorías que reciben por parte de éstas. 
Como resultado de esta evolución, existen ahora varias iniciativas y normativas internacionales a las que han adherido las empresas del sector farmacéutico, o que se hayan en estudio, las cuales se detallan a continuación:

- Directrices de la OCDE

- Principios del Pacto Global

- ISO 14001/EMAS (Esquema Europeo de Auditoría y Gestión Ambiental)

- SGE 21

- $\mathrm{AA} 1000$

- OSHAS 18001

- SA 8000

- Indicadores GRI

En la sección de Referencias y Anexos se cita un resumen de las mismas referenciando a los Laboratorios que las han incorporado a su gestión interna.

\subsubsection{Acciones y programas de Resposabilidad Social Empresaria} (RSE) especificos para las empresas farmacéuticas nacionales e internacionales

En los puntos siguientes se explicitan los requisitos adecuados para demostrar las evidencias de la implantación, en forma integral y estratégica, de la GESR en empresas del sector farmacéutico. Estos requisitos se traducen en acciones y programas de RSE que las empresas deben emprender voluntariamente, ordenadas por un Sistema de Gestión Ética y Socialmente Responsable, para adquirir un compromiso con la sostenibilidad en materia económica, social y ambiental.

Dicho Sistema resulta compatible e integrable con otros Sistemas de Gestión ya implantados, como el de Calidad, Medioambiente, Prevención de Riesgos Laborales, entre otros. Además es verificable. 


\section{a) Tener una persona y departamento a cargo de la RSE}

Para llevar adelante una GESR es necesario contar con un departamento o persona a cargo de la RSE.

Es recomendable que el responsable de dicha gestión tenga un conocimiento exhaustivo tanto de la organización como una formación específica y experiencia demostrada en materia de RSE, para establecer sugerencias con criterio frente a iniciativas legales, estándares voluntarios o propuestas de colaboración.

\section{b) Aplicar formalmente un sistema de gestión económica y socialmente responsable}

Los principales desafíos de la empresa en Argentina en relación a su responsabilidad frente a la sociedad, plantean como punto de partida la necesidad de generar confianza y credibilidad, elementos esenciales para la convivencia. Para lograrlo, es necesario incorporar en la agenda estratégica de la empresa un modelo de gestión ética y socialmente responsable que sustente la interrelación entre políticas, estrategias, comportamientos y procesos. Esto significa enfocar las actividades de la organización aplicando los principios del desarrollo sostenible y tener valores compartidos que aseguren consolidar un comportamiento ético.

Cuando el Gobierno o la Alta Dirección de una empresa decide implantar un modelo de gestión ética y responsable, la primera condición a tener en cuenta es el grado de confianza que tenga en sí misma, en su organización y en sus valores, tales como: transparencia, honradez, buena fe en todos los actos, lealtad, adecuado clima interno, desarrollo de las personas que trabajan en ella, su compromiso con los resultados y la recta intención de difundirlos en el entorno externo, en beneficio de la comunidad local, regional y nacional. De este modo se está en condiciones de avanzar en forma voluntaria en el desarrollo de un compromiso social, con valores éticos y de responsabilidad, para lograr una mejor comprensión y colaboración de todos los grupos involucrados en la vida de la empresa. Así la empresa estará en condiciones, por el compromiso social voluntariamente adquirido, de humanizar las exigencias de la ley y ofrecer 
valor agregado en todas las relaciones con los diferentes grupos de interés o stakeholders.

\section{c) Relación con los grupos de interés}

La Alta Dirección deberá desarrollar un procedimiento para establecer relaciones, efectiva y estratégicamente alineadas, con sus grupos de interés o stakeholders. Éstas sirven para:

- Facilitar una mejor gestión de riesgo y reputación

- Aprender de los stakeholders, lo que genera mejores productos y servicios

- Desarrollar confianza con ellos

- Comprender mejor el contexto complejo de negocios, desarrollo de mercados e identificación de nuevas oportunidades estratégicas.

- Informar, educar e influenciar al entorno empresarial para mejorar procesos de toma de decisiones y acciones que afectan a la compañía y a la sociedad

- Conducir a un desarrollo más equitativo y sostenible al brindar la oportunidad de participar en procesos decisorios a quienes tienen derecho a ser escuchados

- Combinar recursos (conocimiento, personas, dinero y tecnología) para resolver problemas y alcanzar objetivos, que no se pueden lograr en forma independiente.

Para el sector farmacéutico se identifican los siguientes stakeholders:

$\checkmark$ los empleados

$\checkmark$ la comunidad

$\checkmark$ el medio ambiente

$\checkmark$ los consumidores (pacientes)

$\checkmark$ los proveedores

$\checkmark$ las organizaciones sindicales

$\checkmark$ los accionistas

$\checkmark$ las organizaciones no gubernamentales (ONG)

$\checkmark$ las administraciones públicas (Gobiernos)

$\checkmark$ las agrupaciones de empresas farmacéuticas 
$\checkmark$ los medios de comunicación

$\checkmark$ los centros externos de investigación

$\checkmark$ los órganos independientes de evaluación de medicamentos

$\checkmark$ las obras sociales

$\checkmark$ los médicos y personal de la salud

\section{d) Grandes temas de la RSE}

\section{d.1) Valores y principios éticos claramente definidos y comunicados}

La Alta Dirección deberá definir y comunicar en forma clara a la organización los valores y principios éticos, los cuales:

a) Serán adecuados a la organización, alineados con su misión y visión, de manera que integre las directrices principales de gestión.

b) Serán compatibles e integrables con respecto a otras políticas de la organización.

c) Serán publicados, difundidos y estarán a disposición de todas las personas que trabajan para la organización y en nombre de ella.

d) Estarán a disposición pública, de las partes interesadas de la organización, mediante por ejemplo publicaciones, página Web corporativa, intranet, sesiones de comunicación, etc.

e) Estarán aprobados y firmados por el máximo responsable de la organización.

La declaración de valores y principios muestra coherencia y compromiso con la RSE.

\section{d.2) Auditorías periódicas para garantizar el pleno cumplimiento}

\section{de las normas de la empresa y las leyes del país}

El compromiso con la GESR supone ir más allá de lo que la legislación establece. La Alta Dirección garantizará el seguimiento y control de todos aquellos requisitos legales que afectan a su actividad, incluyendo la legislación y normativa que sea específica de su sector, entorno local, ambiental, social y laboral allí donde opere. 
d.3) Política sobre la prevención de sobornos, corrupción y mecanismos para garantizar que se cumple (como capacitación, seguimiento y controles)

La Alta Dirección establecerá una política pública sobre la prevención de sobornos y corrupción que establecerá, entre otras:

a) Medidas para la erradicación de prácticas como el soborno o la extorsión.

b) Criterios de emisión y recepción de regalos y atenciones.

c) Vías para la detección y limitación de los conflictos de intereses.

d) Transparencia frente a la contribución a partidos políticos.

e) Mecanismos de consulta de los empleados ante acciones dudosas.

f) Mecanismos de denuncia contra la corrupción.

Se deberá observar una especial vigilancia en las áreas que se consideren de mayor riesgo de este tipo de prácticas.

\section{d.4) Desarrollo de mecanismos y herramientas de comunicación y reporting}

La Alta Dirección presentará, al menos cada dos años, un informe de la situación de la Responsabilidad Social en su organización, el cual deberá contener como mínimo la siguiente información:

- Perfil de la organización.

- Desarrollo de la estrategia y gestión de la Responsabilidad Social.

- Mecanismos de diálogo con los Grupos de Interés.

- Indicadores económicos, sociales y ambientales. Los indicadores deben ser relevantes y medibles y se presentarán comparados con los correspondientes al periodo anterior.

d.5) Política de calidad claramente definida y comunicada, asumiendo plenamente el compromiso ético que supone la producción y comercialización de medicamentos de uso humano

La organización deberá contar con una política de calidad y con los planes y objetivos que la dirección considere apropiados para conseguir este fin. 
La organización debe operar bajo las estrictas normas GMP (Buenas Prácticas de Manufactura) y, complementariamente, las normas de calidad (ISO 9000), cumpliendo así con los más exigentes parámetros farmacotécnicos relacionados al proceso de producción, a la calidad de elaboración y la comercialización de productos farmacéuticos.

\section{d.6) Desarrollo de buenas prácticas a lo largo de todo el proceso de relación con el consumidor}

\section{d.6.1) Visitadores médicos (APM)}

La organización debe tener un conjunto de hombres y mujeres constantemente capacitados y actualizados a través de cursos, ateneos y seminarios, además de la entrega permanente de información científica, siempre priorizando y atendiendo las necesidades específicas y requerimientos de los profesionales de la salud y sus instituciones.

\section{d.6.2) Consultas Médico - Farmacéuticas}

La organización deberá asignar profesionales idóneos para todas las consultas relativas a cada producto.

\section{d.6.3) Atención a usuarios. Orientación al Consumidor}

El Servicio de Orientación al Consumidor deberá brindar asesoramiento y orientación respecto del plan y alternativas de ayuda para pacientes con o sin Obra Social o Medicina Prepaga.

\section{d.6.4) Página web}

En la web se debe suministrar la información para los siguientes temas:

- Información Institucional

- Atención al profesional y orientación al consumidor

- Consultas de Consumidores

- Consultas de Profesionales

- Atención a Instituciones

- Quejas y Sugerencias

- Información sobre Productos 
d.7) Influencia dentro de la cadena de suministro para impulsar los estándares de comportamiento ético

La organización, en la medida de sus posibilidades, colaborará con sus proveedores y distribuidores en el diseño y revisión de la GESR, compartiendo conocimiento y/o medios técnicos o humanos.

La organización debería establecer planes de acción para trabajar con aquellos proveedores con mayores riesgos en materia social y ambiental. Entre otras iniciativas, la organización podrá:

- Establecer mecanismos de diálogo y aprendizaje.

- Evaluar y/o auditar.

- Facilitar la formación en Responsabilidad Social a sus proveedores.

- Establecer incentivos.

d.8) Política claramente definida y comunicada que condenan la discriminación sobre la base de raza, color, edad, género, orientación sexual, etnia, religión, afiliación política, afiliación sindical o de estado civil

\section{d.8.1) Gestión de la diversidad}

Se identificarán los distintos perfiles de diversidad presentes en la organización, priorizando sus expectativas y necesidades y estableciendo planes de acción que garanticen una gestión responsable de dicha diversidad.

La Gestión de la diversidad en una organización supone ser capaz de integrarlas de modo que sea posible avanzar hacia objetivos comunes y compartidos y hacer coincidir los valores, estructura y objetivos corporativos con las preferencias y necesidades de los profesionales que constituyen la organización.

\section{d.8.2) Igualdad de oportunidades y no discriminación}

La organización garantizará el respeto del Principio de Igualdad de Oportunidades, de forma específica en el acceso a los puestos de trabajo, la formación, el desarrollo profesional y la retribución.

Asimismo, se garantizará la ausencia de discriminación por circunstancias de género, origen racial o étnico, religión o convicciones, 
discapacidad, edad u orientación sexual o cultura, entre otras. Y controlará expresamente que su personal no sea destinatario de conductas no deseadas que tengan como objetivo o consecuencia el atentado contra la dignidad o la creación de un entorno intimidatorio, humillante u ofensivo.

\section{d.9) Política claramente definida y comunicada sobre el trabajo infantil según como se define por las leyes de los países en los que la compañía opera}

La Alta Dirección establecerá una política pública sobre el cumplimiento de los Derechos de la infancia y la juventud (supresión de la explotación infantil y trabajos forzados). La organización deberá identificar las actividades o delegaciones en las que existe un riesgo potencial de incidentes de explotación infantil o trabajos forzados y el desarrollo de las medidas oportunas para contribuir a su eliminación.

\section{d.10) Sistema de evaluación y mejora continua en salud, seguridad} y bienestar en el trabajo (en las operaciones de la empresa, a lo largo de toda la cadena de suministro, en las comunidades donde opera)

La organización desarrollará los mecanismos que garanticen la seguridad y salud en su actividad, que habrá de quedar integrada en todas sus áreas de gestión. Asimismo, garantizará el cumplimiento de las disposiciones en materia de prevención de riesgos laborales.

La organización demostrará que garantiza la salud y seguridad de sus empleados fomentando una auténtica "Cultura de Prevención", integrando la misma e implantando ésta a todos los niveles jerárquicos de la organización. Para ello se sugiere que establezca y documente las bases de un sistema preventivo a fin de asegurar la integridad física y psicológica de las personas que trabajan para la organización y aquellas inherentes a sus propias instalaciones.

Una gestión activa en materia de prevención de riesgos debe incluir los siguientes aspectos:

- un diagnóstico de situación

- designación de un responsable de PRL (Prevención Laboral) 
- establecimiento de un plan de acción con objetivos y metas

- evaluación de riesgos

- investigación de incidentes, accidentes laborales y enfermedades profesionales, sean cuales fuere su carácter o calificación (leves, graves, muy graves o mortales)

- orientación de mejora continua.

- información de los riesgos generales y formación específica de los riesgos inherentes a cada puesto de trabajo.

- los riesgos psicosociales (principalemente Mobbing o Acoso Laboral, el Bullying o Acoso entre Iguales, acoso sexual y el Síndrome del Burnout o Síndrome del Quemado así como el estrés laboral)

\section{d.11) Establecimiento de acciones con repercusión positiva en la comunidad}

En caso de realizar este tipo de acciones, como por ejemplo Programas sociales de educación sanitaria, de lucha contra la enfermedad o de donación de producto, ha de existir un registro para su seguimiento.

La organización debería contemplar:

- Los distintos formatos de colaboración existentes, económicos o no (cesión temporal de recursos, voluntariado corporativo, patrocinios, etc.).

- Proceder a dar un sentido estratégico a la acción social para garantizar su sostenibilidad (alineación con los objetivos estratégicos de la compañía).

- Formalizar la relación con las entidades con las que se colabore y el seguimiento de los resultados, exigiendo cuando sea necesario a las entidades que le proporcione información sobre los resultados de los proyectos y contenido de los mismos.

La información puede ser incluida en una memoria de sostenibilidad o ser publicada de manera independiente.

d.12) Sistema de gestión que le permite desarrollar e implementar una política y objetivos que tengan en cuenta los requisitos legales y otros requisitos a los que la organización suscribe sobre medioambiente y cambio climático 


\section{d.12.1) Prevención de la contaminación y estrategia frente al cambio climático}

La organización se comprometerá públicamente a prevenir la contaminación generada por sus operaciones y productos, incluyendo estrategias contra el cambio climático, así como a mejorar de forma continua su desempeño ambiental favoreciendo el objetivo global de desarrollo sostenible.

La organización deberá hacer manifiesto su compromiso con la prevención de la contaminación y con el desarrollo sostenible, incluyendo su estrategia frente al cambio climático.

\section{d.12.2) Identificación de actividades e impactos}

La organización identificará, registrará y evaluará aquellos aspectos de sus actividades, productos y servicios que causan o pueden causar impactos al medio ambiente.

Se recomienda que se consideren entre otros los siguientes:

- Consumo de Materias Primas

- Consumo de Energía (clasificadas por fuente)

- Consumo de Agua

- Contaminación atmosférica: emisiones de gases de efecto invernadero (GEI), tanto directas (por consumo de fuentes de energía primarias, como combustibles) como indirectas (por consumo de electricidad), así como de otros gases contaminantes y partículas.

Vertidos en aguas y suelo.

- Residuos y subproductos (especificando también los destinos)

- Conservación del medio: afectaciones sobre la biodiversidad o espacios naturales, impacto paisajístico y elementos arquitectónicos de interés cultural.

- Iniciativas correctoras: introducción de energías renovables o compensación de emisiones (compra de certificados de emisiones, plantación de árboles, compensación de emisiones de $\mathrm{CO} 2$ con entidades dedicadas, etc.)

Una vez identificados deberá establecer los mecanismos para evaluarlos y así poder llevar un seguimiento de los mismos. 


\section{d.12.3) Programa de Gestión Ambiental}

La organización establecerá un programa de gestión con objetivos y metas medibles y coherentes con su compromiso ambiental para sus plantas o centros de trabajo con el objetivo de mejorar los impactos en el entorno producidos por sus actividades.

Este programa se revisará anualmente y siempre que se produzcan cambios en la organización que pudieran afectar a la identificación vigente.

El programa debería incluir para cada objetivo la asignación de responsabilidades, los plazos, los medios y los recursos necesarios, así como los indicadores para medir su grado de cumplimiento.

\section{e) Desarrollo equilibrado de la RSE en las áreas funcionales de la empresa y en las unidades estratégicas de negocio (integración funcional en la estructura empresarial)}

\section{e.1) Recursos Humanos}

La gestión del Capital Humano constituye uno de los aspectos más delicados en la vida y desarrollo de las organizaciones, especialmente cuando la empresa trata de implantar un modelo de gestión ética y responsable, que debe tratar siempre a las personas que la integran con respeto, dignidad, honestidad, diálogo, transparencia y sensibilidad. Debe asegurar la igualdad de trato y oportunidades, la ausencia de discriminación por cualquier causa, compatibilizar los objetivos de la compañía con el desarrollo profesional de cada individuo y fomentar las buenas relaciones internas que contribuyan a conciliar la vida laboral, personal y familiar.

\section{e.2) Compras}

Los proveedores y contratistas son una pieza clave para cualquier organización o empresa y se plantea una muy importante relación con cada uno de ellos, a través de la gestión o función de Compras. Entre esos proveedores o contratistas algunos reúnen el carácter de estratégicos, por el impacto de sus suministros en los resultados de la empresa compradora. En todos los casos, aunque principalmente en las relaciones con 
proveedores estratégicos, se plantea la necesidad de establecer una relación basada en la exigencia y el respeto. Esto se consigue con la voluntad de ambas partes y con el cumplimiento de los contratos y su permanente revisión, para lograr la mejora continua de esas relaciones.

De allí la importancia de tener establecido un Sistema de Gestión Ética y Socialmente Responsable que sea capaz de generar la base de confianza adecuada. Por eso la organización debe establecer, implantar y mantener procedimientos para evaluar y seleccionar sus proveedores y subcontratistas, teniendo en cuenta su capacidad de cumplir, entre otros aspectos, los requisitos propios de ese sistema. Esto implica emprender procesos que permitan tomar en consideración el impacto económico social y ambiental de sus proveedores y trasladar a estos los criterios de exigencia equivalentes a los de la propia cadena logística. Para ello la organización podrá clasificar a sus proveedores en función de su grado de criticidad, atendiendo al porcentaje del volumen de compras y el riesgo asociado de los proveedores en relación a sus procesos estratégicos.

En las relaciones internacionales con proveedores del exterior, se recomienda tener en cuenta las normas y disposiciones de la OCDE (Organización para la Cooperación y el Desarrollo Económico), como así también de los convenios de la OIT (Organización Internacional del Trabajo) que sean aplicables.

Con el fin evitar conflictos de intereses con los empleados, es altamente recomendable establecer, implantar y mantener un código de buenas prácticas con relación a la aceptación de regalos, préstamos, servicios, pagos o tratos especiales de cualquier proveedor o subcontratista con el que tenga o pretenda tener tratos comerciales.

\section{e.3) Comercialización}

Se deberá cuidar el desarrollo de buenas prácticas a lo largo de todo el proceso de relación con los pacientes.

\section{e.3.1) Trazabilidad}

Se deberá contar con un sistema de trazabilidad que aporte transparencia en el proceso de distribución de medicamentos, al tiempo 
que brinde seguridad a los pacientes respecto a la calidad del producto que están consumiendo para recuperar o mantener su salud.

\section{e.3.2) Información al paciente}

La información para los pacientes se debe encontrar en todos los envases de los medicamentos. La misma debe ser aprobada por las autoridades regulatorias. Dicha información ayuda a médicos y pacientes a decidir si los beneficios de un determinado medicamento superan los riesgos para pacientes individuales.

\section{e.3.3) Consumo responsable}

Se deberá advetir sobre el consumo responsable. Según la OMS la automedicación es válida en la medida que ésta se practique de manera responsable, sin embargo, la "automedicación responsable" solo está acotada al uso de los medicamentos que no requieren de receta médica. Estos medicamentos, los llamados de Venta Libre u OTC por sus siglas en inglés "over the counter", tienen esta clasificación porque en alguna medida, resultan menos riesgosos que otros, debido a una serie de características farmacéuticas. Las distintas consecuencias del uso indiscriminado de analgésicos, antibióticos u otros fármacos, pueden llegar a ser mortales.

\section{e.3.4) Mejorar el acceso a los medicamentos}

Mejorar la accesibilidad de la población en general a los medicamentos y a la salud debe ser el objetivo de la industria farmacéutica, en especial para los más desfavorecidos, en aquellos lugares donde no pueden conseguir los medicamentos o donde la seguridad social no se hace cargo. Para lograr dicho objetivo, desde luego, es necesaria la colaboración de todos los grupos de interés involucrados en el sector.

\section{e.3.5) Precios diferenciales para los países en desarrollo}

La sociedad en general, y las ONG en particular, demandan que las compañías farmacéuticas tengan políticas de precios especiales para los 
países en desarrollo que atiendan los problemas de salud pública que esos países enfrentan.

\section{e.4) Producción}

\section{e.4.1) Empleados: exposición a sustancias tóxicas}

Siguiendo las GMP, la industria farmacéutica debe considerar los criterios correspondientes para el diseño de las instalaciones destinadas a la fabricación de especialidades medicinales, con el fin de minimizar el potencial riesgo de exposición de los trabajadores por la presencia sustancias tóxicas en el ambiente, así como los requisitos que debe reunir el personal que manipula estas sustancias.

\section{e.4.2) Investigación y Desarrollo (I+D)}

La industria farmacéutica está ligada por la misma esencia del negocio al bienestar de la sociedad y, por tanto, al terreno propio de la RSE. Invertir los recursos necesarios en la investigación y el desarrollo de nuevos productos es el primer compromiso de cualquier empresa del sector.

\section{e.4.3) Calidad}

Es de extraordinaria relevancia invertir en nuevas tecnologías que permitan asegurar la calidad de los productos.

\section{e.4.4) Medioambiente}

Desde el punto de vista de la RSE en la estructura funcional de Producción, la empresa debe comprometerse a prevenir la contaminación generada por sus operaciones y productos, así como a mejorar de forma continua su desempeño ambiental, favoreciendo el objetivo global de desarrollo sostenible. Para ello deberá identificar, registrar y evaluar aquellos elementos de sus actividades, productos y servicios que causan o pueden causar impactos al ambiente.

La conciencia del impacto ecológico de las actividades industriales propias de los sistemas de producción, cuestiona permanentemente la forma de ver el desarrollo. La industrialización en sus diversas manifestaciones y sectores, el uso de recursos no renovables y sus consecuencias sobre la 
naturaleza y el ambiente, ponen en escena la discusión entre visiones positivas vinculadas al progreso y desarrollo y la cara oscura o visión negativa, que muestra el deterioro ambiental que afecta de modo conocido o desconocido a las comunidades, algunas de las cuales lo sufren directamente, cuando empobrecen el suelo, empeoran la salud pública, contaminan el sistema acuífero o el aire, destruyen el paisaje y ponen en serio riesgo y de forma imprevisible e incalculable a todo el planeta. Una perspectiva de mediano o largo plazo, agrega la incertidumbre para las generaciones futuras, que podrán sufrir el impacto de nuestro bienestar, viéndose privadas de disponer de recursos que se tornarán irrecuperables. A esto se refiere la idea de desarrollo sustentable, que supone lograrlo de un modo que sea capaz de satisfacer las necesidades de las presentes generaciones, sin comprometer ni afectar las posibilidades de las futuras, para que puedan disponer de los recursos necesarios que les permitan satisfacer las suyas.

Son de aplicación normas y estándares técnicos, como la serie ISO 14001.

\section{e.5) Finanzas}

La dirección financiera es una de las áreas funcionales que ha experimentado cambios más significativos durante el siglo XX y estos primeros diez años del siglo XXI.

En las empresas bien dirigidas las decisiones estratégicas se toman en forma coordinada y el directivo de finanzas tiene responsabilidad directa de control. Está claro que el objetivo financiero de la empresa es maximizar la rentabilidad para sus accionistas o, lo que es lo mismo, maximizar el precio de la acción. Esto se fundamenta en las siguientes razones principales:

- Es un objetivo sobre el que deben construirse modelos y procesos de decisión.

- Los accionistas, como propietarios de la empresa, eligen su equipo directivo y, en consecuencia, es razonable suponer que la dirección trabajará en interés de aquellos.

- Aún cuando los directivos puedan tener sus propios objetivos, lo norma es que actúen en interés de sus accionistas, procurando maximizar el valor de sus acciones. 
- Toda la gestión está sometida al juicio del mercado. Esto significa que los inversores elegirán las acciones que mejoren más su valor. De allí la importancia de tener en cuenta los factores de los que depende el precio de la acción a fin de establecer si el hecho de que una empresa sea catalogada como responsable en el ámbito social puede favorecer su cotización y aportarle beneficios financieros.

El grupo de los inversores, tanto en lo que se refiere a las empresas que cotizan en Bolsa como las que no, está formado por personas o instituciones que se ven afectados de manera inmediata por las decisiones que toma la Dirección. Las formas de creación de valor deben ser puestas al servicio de toda la comunidad inversora en sentido amplio, integrando accionistas y otros agentes que se ven directamente afectados por su evolución: analistas, gestores y partícipes de fondos de inversión, tomadores de obligaciones negociables, asesores financieros, agencias de evaluación de inversiones y riesgo, etc.

La empresa que asume un compromiso de responsabilidad frente a la sociedad, debe contribuir a crear mercados eficientes y transparentes. Para ello, deben ofrecer toda la información que pueda impactar en el comportamiento del mercado, y hacerlo por medios o canales de comunicación que garanticen el fácil acceso en tiempo y sin ningún tipo de restricciones. Se aplican a tal fin, los principios de transparencia, relevancia, veracidad, lealtad y creación de valor de forma sostenible.

Las empresas, independientemente de su tamaño o su admisión para cotizar en los mercados de valores, deben poner a disposición del público un protocolo de relaciones con inversores, en el que se determine las formas y los procedimientos de comunicación e información. En ese protocolo, se deben establecer claramente: a) las relaciones entre propiedad y gestión de la organización; b) el contenido de la información periódica que se pondrá a disposición de los inversores; c) la frecuencia de dicha información y d) las vías puestas a disposición del inversor para solicitar y recibir información en cualquier momento.

Todo hecho relevante que pudiera afectar a los intereses de los inversores deberá ser comunicado de forma inmediata, suficiente, precisa y fiable. 


\section{e.6) Sistemas de Información y Control}

La empresa debe establecer los canales de comunicación que considere necesarios para que la información generada en los sistemas resulte de utilidad para el desarrollo de la comunidad donde actúa, en todo lo que esté vinculado con su desempeño operativo, financiero y económico. Por otra parte, resulta necesario que, a través de sus sistemas de información y control, la gestión responsable de la empresa fomente, junto a otras organizaciones nacionales, internacionales o grupos de interés, la lucha contra el fraude y la búsqueda de soluciones para evitar la corrupción.

\section{e.7) Auditoría Interna}

Las aplicaciones más significativas de la Auditoría Interna no sólo se refieren a validar la honestidad y veracidad de los estados económicofinancieros, sino que también sus servicios y alcances tienen que cumplir la función de apoyo para que la dirección pueda tomar decisiones correctas en cada una de las áreas o situaciones en que deba intervenir. Sus objetivos principales se identifican con ofrecer una garantía razonable de que los activos de la empresa están preservados de forma apropiada y que los registros financieros se llevan con adecuada y suficiente precisión y confiabilidad para respaldar los estados contables correspondientes. Es también función de la Auditoría Interna ayudar a administradores y gerentes a evaluar la eficiencia en todos los procesos y operaciones de la empresa. Asimismo, debe evaluar que el sistema de control funcione eficazmente en cumplimiento de los objetivos de la organización y podrá emitir dictamen sobre la precisión y utilidad de los informes internos y externos de la empresa.

Finalmente, en esta síntesis sobre la función de Auditoría Interna, es necesario mencionar que debe emitir recomendaciones tendientes a mejorar tanto los procesos operativos como los sistemas de control. 
e.8) Unidades estratégicas de Negocios (Líneas de producto o procesos de negocio)

Dichas unidades definen cómo compite la organización en ese segmento de mercado.

Para la implementación de un modelo de GESR, ésta no debe recaer nunca y en ningún caso en un solo área funcional de RSE sino en aquellos que están cerca de cada stakeholder, es decir, en todas y cada una de las unidades de negocio y de las áreas funcionales. La RSE no es funcional sino estratégica, y esa es la base conceptual y experimentada que debe llevar a ponerla en su lugar en la organización formal.

\section{f) Políticas de RSE globales/regionales o locales}

La estrategia de RSE de una empresa multinacional debe combinar sus objetivos globales y locales, para cada país en el que opera. Así considera como variables relevantes las de carácter institucional, las expectativas, valores, percepciones y necesidades de los grupos de interés.

\section{g) Presupuesto asignado a acciones de RSE}

Se deberá designar un presupuesto a la RSE. Esto demuestra un comprimiso extendido y posiciona a la organización en un nivel más próximo a la decisión formal de implementar y mantener un Sistema de Gestión Ética y Socialmente Responsable para la gestión de sus negocios.

\section{Metodología de la Investigación}

\subsection{Población y Muestra}

Población: en Argentina el sector farmacéutico y farmoquímico posee la estructura que se enseña a contiuación. 


\section{Argentina}

230 laboratorios

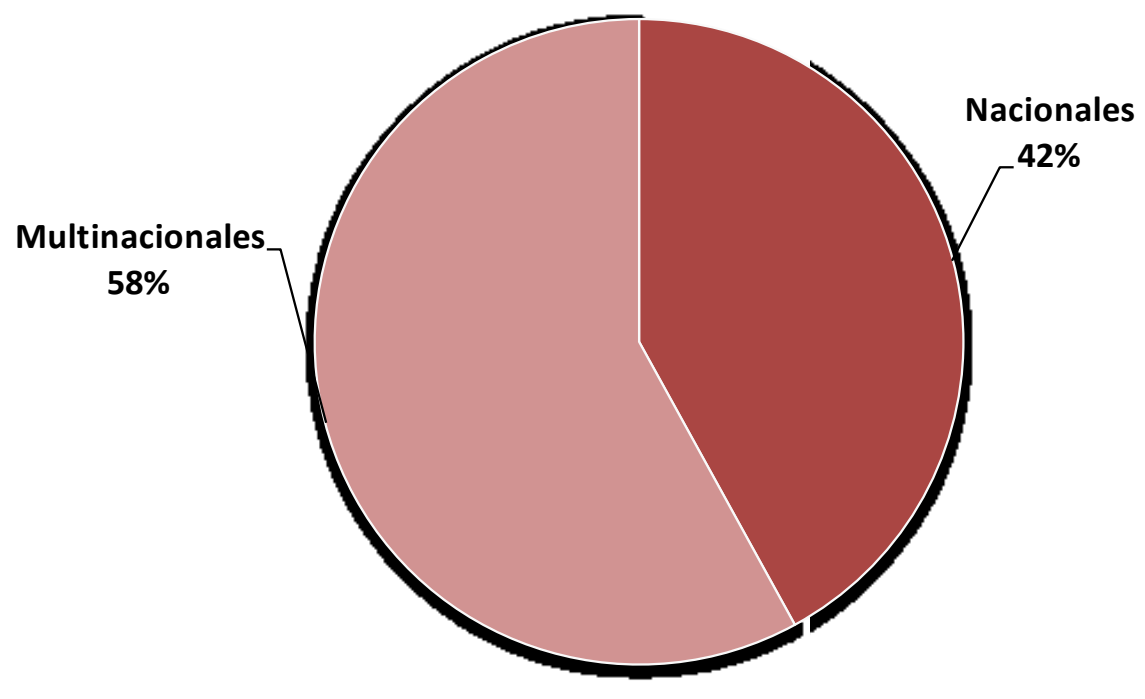

Estructura sectorial - principales indicadores

\begin{tabular}{|l|c|}
\hline Laboratorios & 230 \\
\hline Plantas manufactureras & 110 \\
\hline Capital nacional & 93 \\
\hline Multinacionales & 17 \\
\hline Empleados & 27.000 \\
\hline Número medio de empleados por laboratorio & 95 \\
\hline
\end{tabular}

Fuente: Cámara Industrial de Laboratorios Farmacéuticos Argentinos (CILFA)

Muestra: es no probabilística. Como se refirió en el alcance, el criterio de selección se corresponde con los Laboratorios con mejor percepción en torno a la RSE.

\subsection{Tipo de Investigación}

\section{Exploratoria.}

\subsection{Técnicas de Recolección de Datos}

Se elaboró un cuestionario (ver Referencias y Anexos) que se dirigió por correo electrónico a personas a cargo del área de RSE en los Laboratorios seleccionados para eviderciar el grado de desarrollo de la GESR y el 
compromiso con la misma. En algunos casos se complementó con una entrevista y/o llamada telefónica.

Dicho cuestionario se confeccionó teniendo en cuenta las acciones y programas de RSE específicos para las empresas farmacéuticas nacionales e internacionales, según punto 5.2.3.

Asimismo para ampliar el análisis sobre acciones y programas de RSE, se revisaron los contenidos que han publicado los Laboratorios en cuestión en sus websites corporativos y en la Revista Mercado, en su edición de noviembre de 2010. En la sección de Referencias y Anexos se resume parte de esta información.

Por último, se consultaron otros websites relacionados a Normas de RSE donde aparece información sobre estas empresas.

\subsection{Técnicas de Análisis}

Una vez ordenada, tabulada y elaborada la información recogida, se realiza su presentación en forma sistemática por medio de una representación tabular o gráfica, según resulte conveniente.

\section{Resultados de la Investigación}

Los resultados que se muestran a continuación surgen de las respuestas del cuestionario dirigido a las personas a cargo del área de RSE en los Laboratorios Bagó, Bayer, Novartis, Roche y Roemmers. Las respuestas recibidas están referidas a las filiales de Argentina.

Debido a esta discreción a lo local, para ampliar el análisis sobre acciones y programas a nivel internacional, se revisaron en sus websites corporativos los contenidos sobre RSE. Por otro lado se consultó, en su website oficial, el Listado de empresas que han aplicado los Indicadores GRI. Se citan los enlaces.

Los resultados se exponen en forma ordenada de acuerdo a la secuencia de preguntas establecida en el cuestionario. Los comentarios presentados luego de los gráficos o tablas no incluyen "conclusiones" ni "recomendaciones"; éstas se disponen en los acápites correspondientes. 


\subsection{Organización de "RSE"}

El objetivo de este apartado es indagar acerca de los modos de gestión interna de RSE en términos de la estructura de la organización.

P.1. En su empresa, ¿la gestión de RSE está a cargo de un responsable?

P.2. ¿Tiene su empresa un departamento o área de RSE?

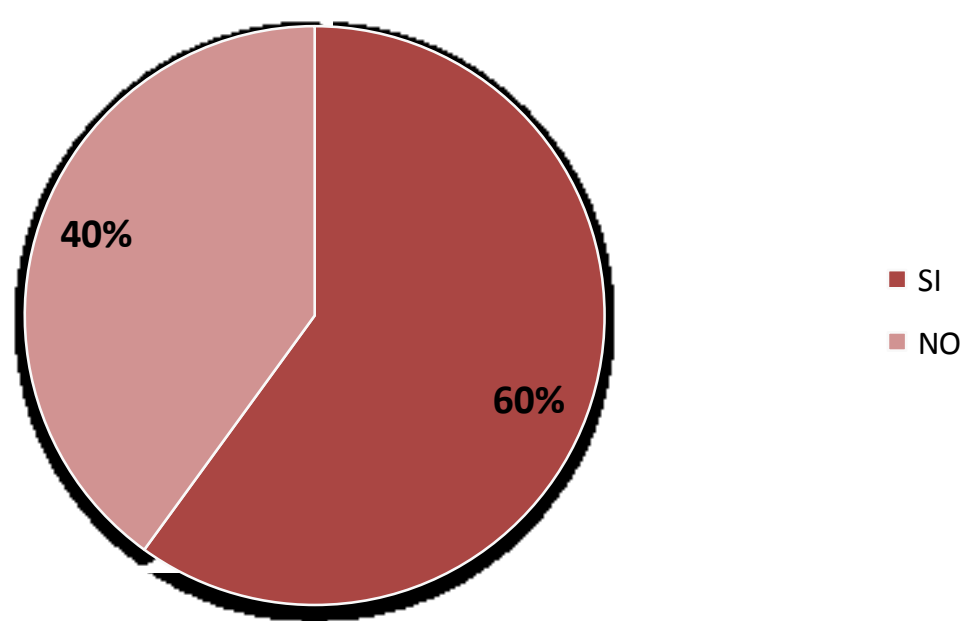




\section{P.3 ¿De quién depende el responsable de RSE?}

\begin{tabular}{|c|c|c|}
\hline & Laboratorio & Observaciones \\
\hline Del Directorio & --- & ---- \\
\hline De la Gerencia General & Roemmers & --- \\
\hline $\begin{array}{lcl}\text { Del área de } & \text { Relaciones } \\
\text { Institucionales } & & \\
\end{array}$ & Bagó & --- \\
\hline Del área de Recursos Humanos & Bayer & $\begin{array}{l}\text { Formalmente depende de } \mathrm{RRHH} \\
\text { pero en la práctica cada vez tiene } \\
\text { más injerencia Relaciones } \\
\text { Institucionales, sobre todo desde el } \\
\text { relanzamiento del programa } \\
\text { UNES*. }\end{array}$ \\
\hline & Roche & --- \\
\hline De otra área (especificar) & Novartis & $\begin{array}{l}\text { Comunicaciones } \quad \text { y } \\
\text { Públicos }\end{array}$ \\
\hline
\end{tabular}

* UNES, Utilicemos Nuestro Espíritu Solidario (ver Referencias y Anexos)

\subsection{Gestión Ética y Socialmente Responsable (GESR)}

El relevamiento de programas y acciones de RSE tiene por propósito verificar el grado en que la GESR forma parte integral de la empresa. Cuando se refiere a GESR se hace alusión a la manera en que las empresas llevan a cabo sus operaciones y al grado en que incorporan los aspectos económicos, sociales y ambientales a la estrategia de negocios.

P. 4. ¿Su empresa aplica formalmente o tiene en estudio alguno de estos sistemas de gestión económica, social y ambientalmente responsable como iniciativas de RSE?

\section{A nivel local (Argentina):}

\begin{tabular}{|l|c|c|c|c|c|}
\hline & Bagó & Bayer & Novartis & Roche & Roemmers \\
\hline Directrices de la OCDE & --- & --- & --- & --- & -- \\
\hline $\begin{array}{l}\text { Principios del Pacto } \\
\text { Global }\end{array}$ & $\mathrm{X}$ & $\mathrm{X}$ & $\mathrm{X}$ & --- & $\mathrm{X}$ \\
\hline $\begin{array}{l}\text { ISO 14001/EMAS } \\
\text { (Esquema Europeo de } \\
\text { Auditoría y Gestión }\end{array}$ & $\mathrm{X}$ & --- & --- & --- & \\
\hline SGE 21 & --- & --- & --- & --- & --- \\
\hline AA 1000 & --- & --- & --- & --- & --- \\
\hline OSHAS 18001 & $\mathrm{X}$ & --- & --- & --- & --- \\
\hline SA 8000 & --- & --- & --- & --- & --- \\
\hline Indicadores GRI & $\mathrm{X}$ & --- & --- & --- & -- \\
\hline Otro (indicar) & --- & --- & --- & Principios & Corporativos \\
\hline
\end{tabular}




\section{A nivel Internacional (empresas de origen extranjero):}

\begin{tabular}{|l|c|c|c|}
\hline $\begin{array}{l}\text { ISO 14001/EMAS } \\
\text { (Esquema Europeo de } \\
\text { Auditoría y Gestión }\end{array}$ & $\mathrm{X}$ & $\mathrm{X}$ & Lineamientos \\
\hline SGE 21 & --- & $\mathrm{X}$ & - --- \\
\hline OSHAS 18001 & $\mathrm{X}$ & $\mathrm{X}$ & Lineamientos \\
\hline Indicadores GRI & $\mathrm{X}$ & $\mathrm{X}$ & $\mathrm{X}$ \\
\hline
\end{tabular}

Fuentes:

http://www.bayer.com/en/sustainability-at-bayer-2009-2010.pdfx

http://www.corporatecitizenship.novartis.com

http://www.novartis.es

http://www.roche.com/corporate_responsibility/environment.htm

http://www.globalreporting.org/ReportServices/GRIReportsList/

Se puede apreciar que existe en tres de ellos una adhesión a los Principios de Pacto Global de Naciones Unidas (The Global Compact). Asimismo a nivel local, sólo los Laboratorios nacionales han desarrollado la normativa referida a medioambiente (ISO 14001), mientras que los multinaciones lo han hecho en otras de sus filiales. Algo similar ocurre con la Norma de Gestión de la Seguridad y Salud OSHAS 18001. En particular, cabe destacar que el Grupo Roche toma los lineamientos de las normativas mencionadas y los traduce en Principios Corporativos, Políticas y Directrices para el aseguramiento de Seguridad, Salud y Protección del Medio Ambiente.

Por otro lado en materia de reporting, las filiales locales de las multinacionales no aluden a la elaboración de los reportes corporativos de sustentabilidad (Indicadores GRI), aunque sí lo hacen a nivel de su casa matriz. En la conversación mantenida con su responsable, sólo Bagó ha mencionado tenerlos en estudio. Por lo analizado, se observa que momentáneamente difunden las acciones de RSE que llevan a cabo mediante la actualización en su website corporativo o Revistas donde se publican estudios sobre RSE (ver Referencias y Anexos).

La norma SGE 21 está iniciando recientemente su difusión en la Argentina. Novartis la ha implementado en su filial de España. 


\section{P.6. Identifique 5 grupos de interés (stakeholders) prioritarios en relación con la gestión responsable de su empresa.}

\begin{tabular}{lc}
\hline Grupos de Interés & Opciones \\
\hline los empleados & 5 \\
\hline los consumidores (pacientes) & 4 \\
\hline los médicos y personal de la salud & 4 \\
\hline la comunidad & 3 \\
\hline el medio ambiente & 3 \\
\hline los accionistas & 2 \\
\hline los proveedores & 1 \\
\hline las administraciones públicas (Gobiernos) & 1 \\
\hline los medios de comunicación & 1 \\
\hline los centros externos de investigación & 1 \\
\hline
\end{tabular}

Se observa que en materia de RSE, los empleados; pacientes; médicos y personal de la salud; la comunidad y el medio ambiente son el eje de las acciones $\mathrm{o}$ actividades efectuadas.

Se evidencia que la elección de los principales grupos de interés está en concordancia con las directrices de Pacto Global a la que adhieren los Laboratorios, que refieren a Derechos Humanos, Estándares Laborales y Medio Ambiente.

De acuerdo a las respuestas recibidas, las dos multinacionales más grandes, Bayer y Roche, señalaron a los accionistas como un grupo de interés prioritario.

En la próxima pregunta sobre el grado de desarrollo de la gestión responsable de la empresa con relación a los grandes temas de RSE se observará la correlación que estos tienen con los grupos de interés seleccionados. 


\section{P (7 a 18) ¿Cuál es el grado de desarrollo de la gestión responsable de} su empresa con relación a los siguientes temas de RSE?

16. Salud, seguridad y bienestar en el trabajo

15. Política sobre Trabajo infantil

14. Diversidad y discriminación

13. Cadena de suministro

12. Relación con el consumidor

11. Política de calidad

10. Comunicación y reporting

9. Prevención de sobornos y corrupción

8. Normas de la empresa y requisitos legales

7. Valores y Principios
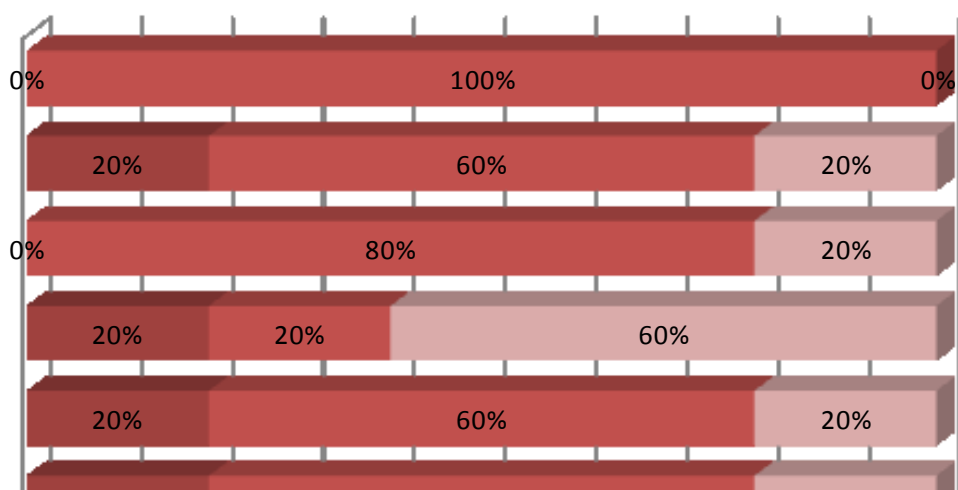

- Medio

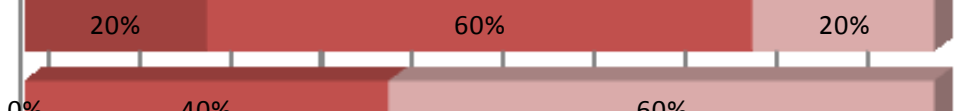

Alto

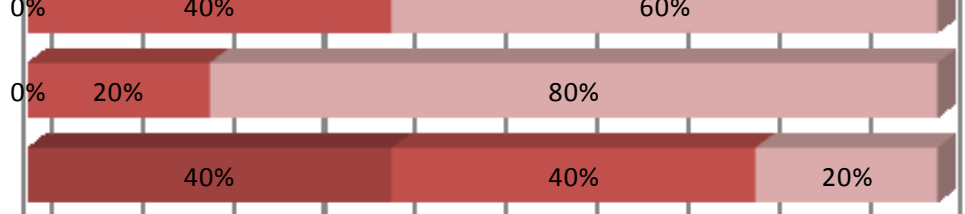

Muy alto

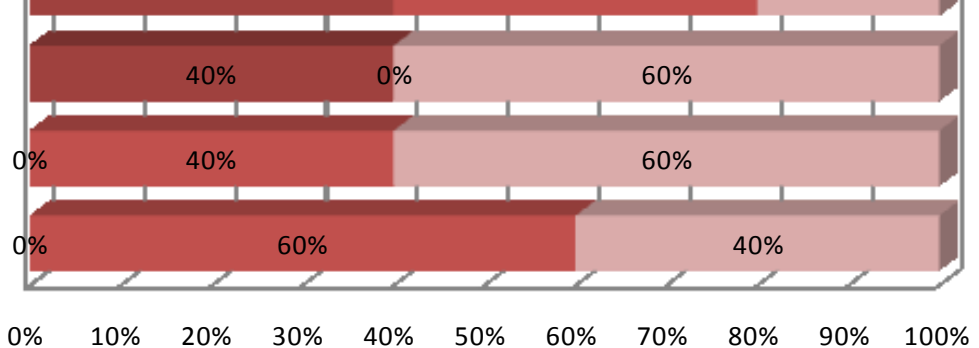

Los encuestados han afirmado que la mayoría de los grandes temas de RSE están desarrollados en un grado "Alto" o "Muy Alto". Se podría decir que en un grado "Medio" se encuentran la "Política sobre prevención de sobornos y corrupción" y los "mecanismos y herramientas de comunicación y reporting".

A continuación se indica el impacto de estos temas en relación a los grupos de interés señalados como prioritarios. 
Fundamentos y pautas para una Gestión Ética y Socialmente Responsable (GESR)

Aplicación en empresas del sector farmacéutico

\begin{tabular}{lccccc}
\hline & Empleados & Pacientes & P. Salud & Comunidad & M. Ambiente \\
\hline Valores y Ppios. & $\mathbf{X}$ & $\mathbf{X}$ & $\mathbf{X}$ & $\mathbf{X}$ & $\mathbf{X}$ \\
Normas y leyes & $\mathbf{X}$ & & & $\mathbf{X}$ & $\mathbf{X}$ \\
Soborno y Corrup. & $\mathbf{X}$ & & & & \\
Reporting & $\mathbf{X}$ & $\mathbf{X}$ & $\mathbf{X}$ & $\mathbf{X}$ & $\mathbf{X}$ \\
Calidad & & $\mathbf{X}$ & $\mathbf{X}$ & $\mathbf{X}$ & \\
Relación Consum. & & $\mathbf{X}$ & $\mathbf{X}$ & & \\
Proveedores & & & & $\mathbf{X}$ & $\mathbf{X}$ \\
Diversidad & $\mathbf{X}$ & & & & \\
Trab. Infantil & $\mathbf{X}$ & & & & \\
Salud y Seguridad & $\mathbf{X}$ & & & & \\
Acción Social & & & & & \\
Medio Ambiente & & & & & \\
\hline
\end{tabular}

\section{P (19 a 27). ¿Existen acciones concretas de RSE asociadas a las siguientes áreas en su empresa?}

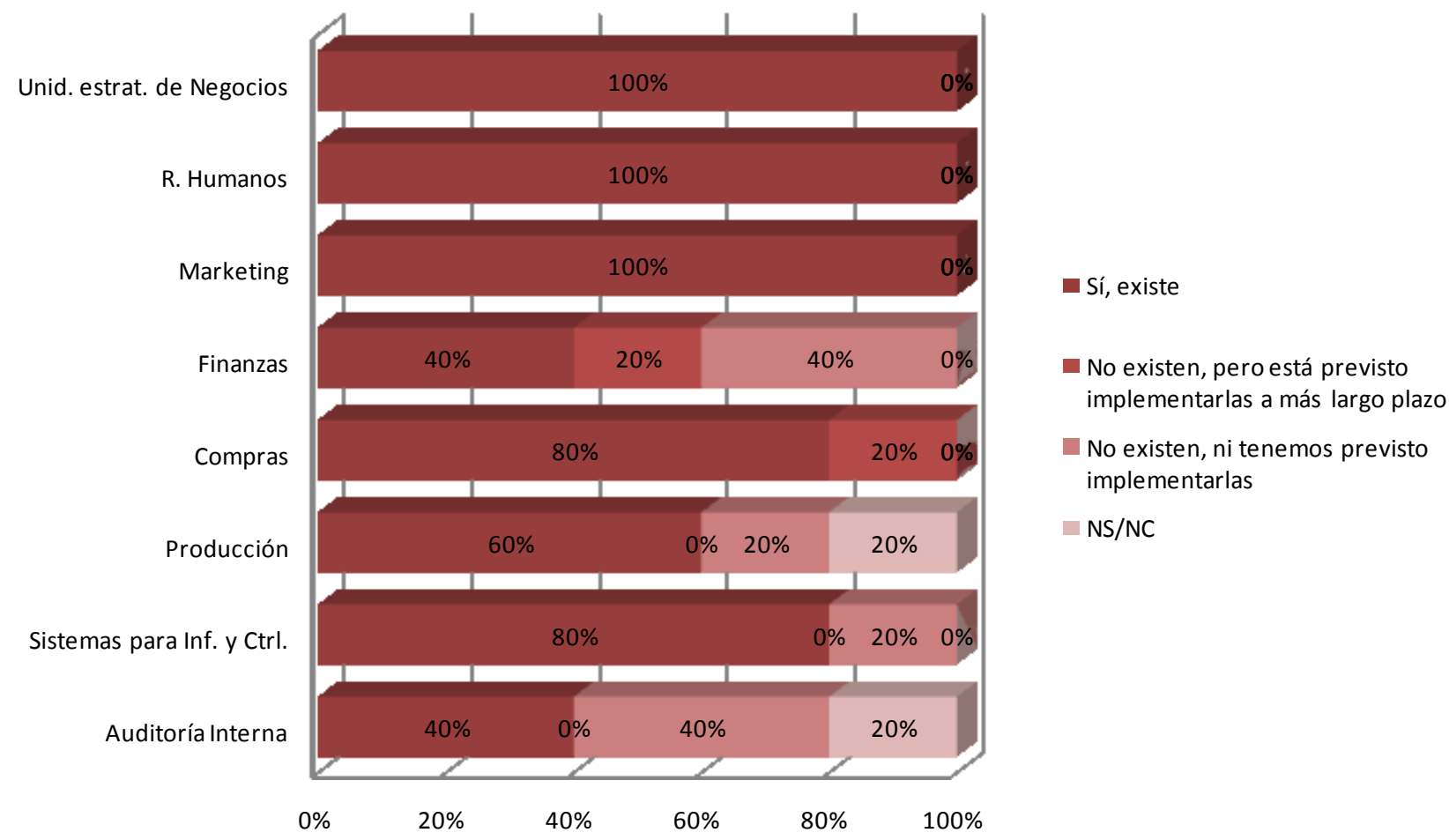

Teniendo en cuenta los resultados acerca del grado de desarrollo de la gestión responsable en las empresas en relación a sus grupos de interés y a los grandes de temas de la RSE, se evidencia una correspondencia con 
el 100\% de los encuestados que señaló que existen acciones concretas de RSE asociadas al Área de Recursos Humanos, por los empleados, y a las Unidades Estratégicas de Negocios y al Área de Marketing, por los pacientes, médicos y personal de la salud. Asimismo teniendo en cuenta a los Laboratorios que producen en el país (Bagó, Bayer y Roemmers), la totalidad de ellos contemplan las acciones de RSE en las Áreas Productivas con su consecuente impacto en los empleados y el medio ambiente.

En un nivel muy alto de integración funcional $(80 \%)$ también se llevan a cabo acciones de RSE en el Área de Compras y de Sistemas para Información y Control.

Finalmente, continuado con un análsis por estratos, en el inferior se hayan las Áreas de Finanzas y Auditoría Interna.

\section{P.28 ¿Las políticas de RSE responden a políticas globales/regionales o son específicas al país?}

\section{Laboratorio Políticas de RSE}

\begin{tabular}{ll}
\hline Bagó & Específicas al país, que de acuerdo a su aplicabilidad se \\
& desarrollan a nivel global. \\
Bayer & Hay políticas globales, pero en el caso de UNES es un programa \\
& de voluntariado corporativo que está basado en una política local. \\
& Con respecto a las acciones de RSE hay acciones específicas de \\
& las Unidades de Negocios y luego se invita a todos los \\
& colaboradores a presentar una institución para el programa de \\
& UNES (puede presentar cualquier sector).
\end{tabular}

Novartis Responden a políticas globales

Roche Existe un lineamiento global e iniciativas globales, pero cada país implementa sus propios programas y acciones de RSE.

Roemmers Responden a políticas globales

En los principales programas y acciones en materia de RSE que realizan los Laboratorios arriba mencionados, los cuales se citan en Referencias y Anexos, se puede apreciar claramente cuáles responden a políticas globales y cuáles de ellos están diseñados para el contexto local de Argentina. 
La mayoría de los Laboratorios destacan aquellas acciones que tienen que ver con la comunidad. Se observa que realizan este trabajo vinculados a asociaciones, fundaciones, organizaciones no gubernamentales (ONG), entidades que conforman el denominado "Tercer Sector".

Otra particularidad es que los Laboratorios de origen extranjero resaltan sus actividades en relación al medio ambiente, mientras que los nacionales lo hacen con los médicos y profesionales del área de la salud.

\section{P. 29 ¿Cuenta su empresa con presupuesto asignado a acciones de RSE?}

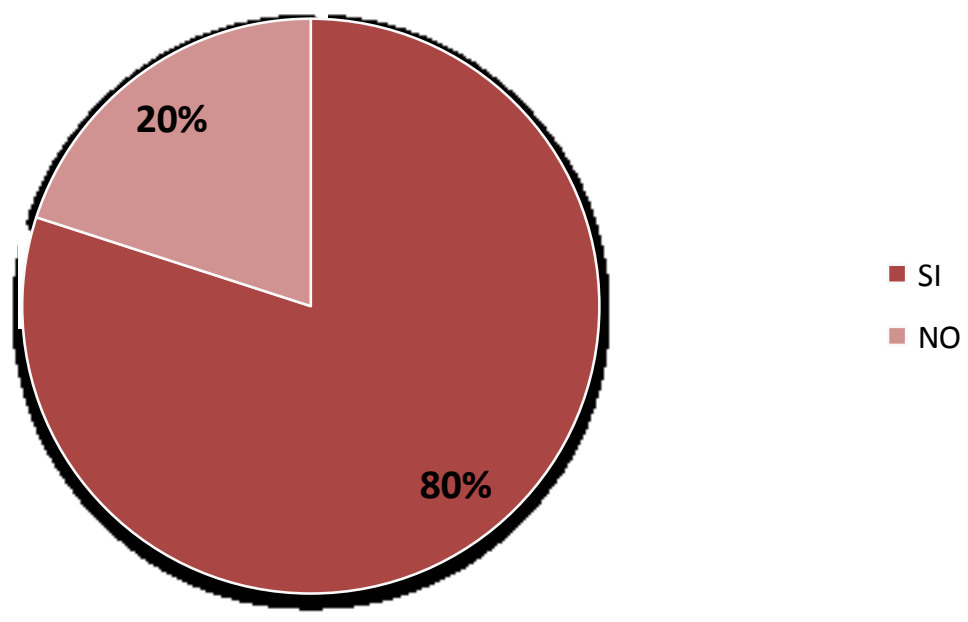

\section{P.30. Respecto del año anterior, el presupuesto:}

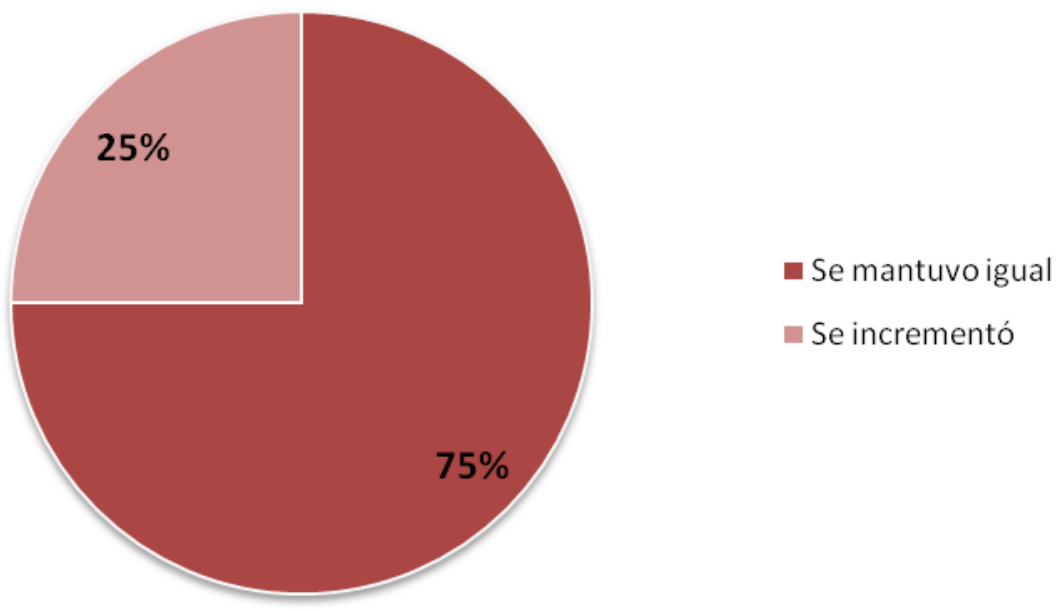

La mayoría de los Laboratorios estudiados cuenta con un presupuesto anual específico para las acciones de RSE, el cual respecto al año anterior se mantuvo igual. 


\section{Conclusiones}

8.1 La demanda natural de RSE al sector farmacéutico debido a su propia esencia y su actividad principal relacionada con la salud y al consecuente impacto en la calidad de vida de la sociedad, motiva a los Laboratorios a identificar su imagen corporativa con la misma, ya sea en la definición del logo, la marca o del eslogan que la acompaña. En referencia a los Laboratorios investigados:

- Bagó. Eslogan: Ética al servicio de la salud

- Bayer. Eslogan: Ciencia para una mejor vida

- Roche. Eslogan: Creando valor para los pacientes

- Roemmers. Eslogan: Conciencia por la vida

- Novartis. El nombre significa "nuevas habilidades" o "innovación". El logo sugiere la flor de la vida...tomado en su conjunto, el nombre y el logo simbolizan una organización basada en la investigación, que no sólo es innovadora, sino que también respeta la humanidad, los animales y el medioambiente (ver http://www.ar.novartis.com/novartis/nuestro-nombre).

Complementariamente en los casos de los dos Laboratorios nacionales, Bagó y Roemmers, son empresas familiares cuyo desempeño social está atado a su apellido y, por lo tanto, son conscientes de que deben estar comprometidos con la comunidad llevando a cabo las acciones que estén a su alcance para lograr ser referentes en la misma.

8.2 Se observa un razonable grado de formalidad en el abordaje de los temas de RSE en los modelos de organización, puesto que en todos los Laboratorios existe un área responsable del tema, aunque no en todos específica, y en algunos de ellos con una persona a su cargo.

8.3. Cabe destacar la importancia que los Laboratorios otorgan a la declaración de Principios y Valores, lo cual muestra coherencia y compromiso con la GESR.

8.4. Para la implantación de la GESR es relevante la primacía señalada de los empleados dentro de los grupos de interés, puesto que en el personal es donde radica toda la base de la GESR. Dicha gestión integral es cosa 
de todos y, por lo tanto, es una obra que resulta de un trabajo conjunto, no sólo de los directivos.

8.5. En correlación con los grupos de interés marcados como prioritarios, podemos concluir que las acciones correspondientes a los grandes temas de RSE, que se desarrollan en su generalidad en un grado "Alto" o "Muy Alto", tienen un impacto muy positivo sobre los mismos. En un nivel medio sólo quedaron las acciones de "comunicación y reporting" y "políticas de prevención de sobornos y anticorrupción".

8.6. Podría concluirse que la GESR evoluciona con una integración funcional en la estructura empresarial de los Laboratorios, pero no existe una plena comprensión de la GESR desde la competitividad, que requiere un desarrollo equilibrado en todas las áreas funcionales de gestión.

8.7. Dado que todas las empresas analizadas comercializan a nivel internacional, resulta substancial que combinen sus objetivos globales y locales, en torno a la GESR, para cada país en el que operan. De esta manera, la GESR se ajusta a las necesidades de los diversos grupos de interés y se alínea a su fin trascendente.

El trabajo mancomunado con el Tercer Sector es vital para el desarrollo del capital social, uno de los mecanismos más importantes a través del cual se logra mejorar el bienestar de los individuos y las comunidades. Se afirma que la RSE es una de las materializaciones del capital social. El incremento de este capital influencia favorablemente al gobierno de las empresas o governance en la medida que permite viabilizar y sostener los contenidos éticos que son también parte de los recursos productivos.

Vale resaltar, bajo esta concepción, los voluntariados corporativos que son emprendidos por los Laboratorios de origen extranjero: Bayer, Novartis y Roche.

8.8. Que la mayoría de los Laboratorios estudiados cuente con un presupuesto anual específico para las acciones de RSE, indica que estas compañías demuestran un compromiso extendido. En la entrevista 
mantenida con el Gerente de Relaciones Institucionales de Bagó, éste afirmó que "la presencia de los propietarios en la organización ha favorecido el impulso y la promoción de recursos para acciones de RSE, aún en contexto de crisis".

Asimismo que los presupuestos mayormente se hayan mantenido igual que el año anterior da indicios que la GESR se orienta lentamente hacia la incorporación estratégica y se aproxima a la aplicación de un Sistema de Gestión Ética y Socialmente Responsable.

\section{Recomendaciones}

Se prevé que en el mediano o largo plazo los Sistemas de Gestión Ética y Socialmente Responsable tengan, para la industria farmacéutica, un carácter singular como son las Buenas Prácticas de Fabricación (BPF) o, en inglés, Good Manufacturing Practices (GMP), puesto que año a año los organismos de control y el mercado a medida que se da cumplimiento a ciertos requisitos anteriores exigen nuevos.

Los resultados de la investigación demuestran que los Laboratorios se encuentran en un nivel relativamente próximo para la implantación de un Sistema de este tipo. Es preciso que avancen en la organización formal y en la documentación del mismo, por medio de las recomendaciones que se detallan a continuación.

9.1 En aquellos Laboratorios que aún no lo han concretado, se sugiere que designen un departamento específico y persona a cargo de la GESR, en especial en estas empresas que cuentan con un gran número de empleados: las que producen en el país superan los 1200 empleados (Bagó, Bayer y Roemmers), mientras que las que comercializan y distribuyen medicamentos (Novartis y Roche) rondan los 400 empleados.

Es primordial que el responsable de dicha gestión tenga un conocimiento exhaustivo tanto de la organización como una formación específica y experiencia demostrada en materia de RSE. 
Este responsable se encontrará a disposición de la Alta Dirección así como de los responsables de las áreas funcionales de gestión para informarles sobre sugerencias, novedades, actividades, nueva legislación, riesgos, premios y cualquier aspecto de la GESR donde los intereses de la organización se puedan ver afectados.

Asimismo, dicho responsable identificará y elaborará la documentación que es necesaria para que el Sistema de GESR sea verificable, considerando las políticas, procedimientos, registros y otros documentos que se comparten con otros Sistemas de Gestión de la organización, como el de Calidad, Gestión Ambiental, Salud y Seguridad Ocupacional.

9.2. Se aconseja la elaboración de los siguientes documentos:

- Política de GESR: adecuada a la organización, alineada con su misión y visión, de manera que integre las directrices principales de gestión. Será compatible e integrable con respecto a otras políticas de la organización.

Incluirá el compromiso voluntario de integrar, en su estrategia y gestión, aquellos aspectos sociales, laborales, éticos y ambientales que superen las exigencias de la legislación. Estará aprobada y firmada por el máximo responsable de la organización.

- Código de Conducta o documento similar donde se haga expresa la declaración de Principios y Valores de la empresa. Asimismo donde se expresen las "políticas de prevención de sobornos y anticorrupción".

Es condición necesaria que estos documentos sean conocidos por todos los integrantes de la organización así como los grupos de interés que se considere.

9.3. Las relaciones con el personal son fundamentales para implementar un Sistema de GESR. En el personal es donde radica la cualidad de conciencia de forma individual y, por lo tanto, es de donde procede toda la base de la Gestión Ética Integral y la toma de conciencia de cada persona. Por tanto es necesario crear y mantener un clima laboral agradable en el que el personal se sienta responsable y participe en los asuntos que les 
afectan a cada uno. El Sistema de GESR está realmente implantado cuando los requisitos éticos se integran en la forma de trabajar rutinaria de los empleados. No debe existir separación entre la Ética y el trabajo.

9.4. Es importante que se refuercen las acciones de "comunicación y reporting" a través de la presentación de una Memoria Anual de RSE. Se aconseja que se emplee una normativa que aporte directrices sobre la elaboración y la comunicación de informes sociales.

9.5. Se sugiere, por último, que la Alta Dirección desarrolle un modelo documentado de relación con los grupos de interés. Para ello se definirán los criterios para identificar y clasificar dichos grupos de interés, así como la metodología para detectar sus expectativas y establecer y priorizar los planes de acción y comunicación.

A modo de comentario final, se presenta esta visión antropológica que puede o no compartirse: el progreso de la sociedad sólo se logra si se tiene en cuenta principalmente a la persona, su entorno y la existencia de condiciones sociales que puedan asegurar - en forma sostenible - el desarrollo de las capacidades humanas, que garanticen una vida digna para todos, sin exclusiones. Es importante comprender que todas las empresas pueden contribuir a crear valor económico creando también valor social a través de la inclusión; en particular las del sector farmacéutico lo pueden hacer de tres formas: innovando en productos y en mercados, mejorando el acceso a los medicamentos y estableciendo precios diferenciales para los países en desarrollo; redefiniendo la productividad en la cadena de valor al promover inclusión mediante el apoyo a micro emprendedores que se incorporen a esa cadena de valor; generando empleabilidad a través de aportes sustanciales en el modelo educativo y cultural, y mediante la aplicación de modelos de gestión de la diversidad, que ayuden a incorporar en el sistema productivo a personas actualmente excluidas. 
Fundamentos y pautas para una Gestión Ética y Socialmente Responsable (GESR) Aplicación en empresas del sector farmacéutico

La acción del Estado y de los demás poderes públicos debe conformarse al principio de subisidiaridad y crear condiciones favorables para este ejercicio del ámbito económico, que busca promover el bien común por medio del desarrollo integral y solidario para la humanidad. 


\section{Bibliografía}

AccountAbility.

Enlace: www.accountability.org/index.html

Administración Nacional de Medicamentos, Alimentos y Tecnología Médica. Disposición 2819/2004. Lineamientos generales de Buenas Prácticas de Fabricación para Elaboradores, Importadores/Exportadores de Medicamentos.

Enlace: www.anmat.gov.ar

Beltramini, H. Busch, A. Sauer, N. 2005. "La evolución de la regulación de medicamentos en Argentina: aspectos técnicos e institucionales". Dirección de Planificación y Relaciones Institucionales Administración Nacional de Medicamentos, Alimentos y Tecnología Médica (ANMAT).

Enlace: www.ag.org.ar/3congreso/Ponencias/Busch.pdf

Castner, Morgan. Hayes, Joanna. Shankle, Daniel. 2007. Duke University. Enlace: www.duke.edu/web/soc142/team2/social.html

European Commission: Environment.

Enlace: http://ec.europa.eu/environment/emas

Forética. 2008. Curso de Gestión de Responsabilidad Social Empresaria.

Forética. 2011. Investigación: "Gestión de la Responsabilidad Empresaria en Empresas vinculadas a ACDE - Año 2010".

Fontrodona Felip, Joan. 2005. Gestión Integral de la RSE: El caso de Novartis en España.

Enlace:www.foretica.es/recursos/doc/Biblioteca/Cuadernos_Foretica/124_1 93193200817323.pdf

García Lombardía, P. de la Torre García, C. Fuertes Zurita, A. "El desafío empresarial de la gestión de la Responsabilidad Social Corporativa: un 
enfoque sectorial". Avanzando hacia una empresa socialmente responsable. Vol. I. IESE-Universidad de Navarra. CR WORKS Responsabilidad Corporativa. 2007.

García Martinez, Virtudes. 2006. La Responsabilidad Social Corporativa en la industria farmacéutica. Número Monográfico: Responsabilidad Social Corporativa. Training \& Development Digest. Número 58.

Global Reporting Initiative (GRI)

Enlace: www.globalreporting.org

International Organization for Standardization

Enlace: www.iso.org

García Lombardía, P. de la Torre García, C. Fuerte Zurita, A. 2007. El desafío empresarial de la gestión de la Responsabilidad Social Corporativa: un enfoque sectorial. Avanzando hacia una empresa socialmente responsable. Vol. I. IESE - Universidad de Navarra.

Enlace: http://insight.iese.edu/casos/Study_0099-S.pdf

Maito, Miguel A. 2010. CPhISOUTH AMERICA 2010. La industria farmacéutica argentina: su carácter estratégico y perspectivas.

Enlace: www.cilfa.org.ar

Melé, D. 2007. Responsabilidad social de la empresa: una revisión crítica a las pricipales teorías. Ekonomiaz: revista vasca de economía. № 65 .

Enlace: http://dialnet.unirioja.es/servlet/articulo?codigo $=2533611$

Oficina de Naciones Unidas para el Pacto Mundial. 2007. Estableciendo la conexión. Guía para la elaboración de memorias de sostenibilidad del GRI y Comunicación del Progreso del Pacto Mundial.

Enlace: www.globalreporting.org

Organización para la Cooperación y Desarrollo Económico 
Enlace: www.oecd.org

Pacto Mundial

Enlace: www.pactomundial.org

Paladino, Marcelo. 2004. La Responsabilidad de la empresa en la sociedad. Construyendo la sociedad desde la tarea directiva. Ed. Ariel Sociedad Económica.

Preziosa, María Marta. La definición de «Responsabilidad Social Empresaria» como tarea filosófica. Pontificia Universidad Católica Argentina Santa María de los Buenos Aires. Cuad Difus. 10 (18-19). 2005.

Revista Apertura. Marzo de 2011. Ranking las 100 mejores empresas en imagen de la Argentina según los líderes. Edición 208.

Revista Mercado. Noviembre 2009. La nueva dimensión de la RSE. Ranking de las 100 compañías mejor percibidas.

Revista Mercado. Noviembre 2010. Fronteras del pensamiento en RSE. Ranking de las 100 compañías mejor percibidas.

Social Accountability International (SAI), Guidance document for social accountability SA8000.

Enlace: www.sa-intl.org

Strandberg, Lena. 2009. La medición y la comunicación de la RSE: indicadores y normas. Cuadernos de la Cátedra "la Caixa" de Responsabilidad Social de la Empresa y Gobierno Corporativo. № 9.

World Business Council for Sustainable Development (WBCSD) Enlace: www.wbcsd.org 


\section{Glosario de Términos}

Alta Dirección. Máximo responsable ejecutivo de la organización y aquellos directivos que tengan dependencia directa del mismo.

Calidad. Grado en que un conjunto de características inherentes cumple con los requisitos.

Cambio Climático. Variación estadística significativa en el estado medio del clima o en su variabilidad, que persiste durante un período prolongado (normalmente decenios o incluso más). El cambio climático se puede deber a procesos naturales internos o a cambios del forzamiento externo, o bien a cambios persistentes antropogénicos en la composición de la atmósfera o en el uso de las tierras.

Código de Conducta. Expresión documentada de los valores de la organización que además puede establecer pautas o reglas de acción para casos y circunstancias determinadas $y$, en muchas ocasiones, para personas o puestos de trabajo específicos.

Corrupción. Mal uso del poder encomendado para obtener beneficios privados.

Grupos de Interés o stakeholders. Entidades o individuos a los que pueden afectar de manera significativa las actividades, productos $y / o$ servicios de la organización; y cuyas acciones pueden afectar dentro de lo razonable a la capacidad de la organización para desarrollar con éxito sus estrategias y alcanzar sus objetivos.

I+D+i. Investigación, desarrollo e innovación. Actividad de la organización encaminada a ofrecer una mejora en el proceso de elaboración del producto o servicio, o en su resultado final.

Programa de Responsabilidad Social. Conjunto de acciones definidas, en materia de responsabilidad social, para conseguir los objetivos 
previstos, incluyendo la asignación de responsables y la definición de recursos y tiempos de ejecución necesarios.

Política. Intenciones globales y orientación de una organización respecto a algún aspecto de la gestión tal como se expresan formalmente por la alta dirección.

Prevención de Riesgos Laborales. Disciplina que busca promover la seguridad y salud de los trabajadores mediante la identificación, evaluación y control de los peligros y riesgos asociados a un proceso productivo, además de fomentar el desarrollo de actividades y medidas necesarias para prevenir los riesgos derivados del trabajo.

Proveedor. Se entiende como proveedores a aquellas personas físicas o jurídicas que faciliten productos o servicios a un tercero. A efectos de esta norma, se considera proveedores a aquellos que contratan de manera directa con la empresa (proveedores de primer nivel).

Reporting. Herramienta de comunicación eficaz, sistemática, de apoyo a la gestión, que proporciona transparencia y credibilidad a las actuaciones de las empresas.

Sistema de Gestión. Conjunto formado por la estructura de la organización, responsabilidades, procedimientos, procesos y recursos establecidos para conseguir unos objetivos previamente definidos.

Soborno. Ofrecimiento o aceptación de regalos, préstamos, honorarios, gratificaciones o cualquier otro tipo de beneficios, a o de cualquier persona a modo de incentivo para realizar un acto deshonesto, ilegal o que implica el quebrantamiento de la confianza, durante la conducción de los negocios de la organización. 


\section{Referencias y Anexos}

\subsection{Directrices de RSE}

Líneas directrices de la OCDE para Empresas Multinacionales (Organización para la Cooperación y Desarrollo Económico)

Las Líneas Directrices de la OCDE para Empresas Multinacionales (en adelante, las Directrices) son recomendaciones dirigidas por los gobiernos a las empresas multinacionales. Fueron creadas por la OCDE en 1976 y revisadas en el 2002. Enuncian principios y normas voluntarias para una conducta empresarial responsable compatible con las legislaciones aplicables. La vocación de las Directrices es garantizar que las actividades de esas empresas se desarrollen en armonía con las políticas públicas, fortalecer la base de confianza mutua entre las empresas y las sociedades en las que desarrollan su actividad, contribuir a mejorar el clima para la inversión extranjera y potenciar la contribución de las empresas multinacionales al desarrollo sostenible.

Las empresas deberán tener plenamente en cuenta las políticas fijadas por los países en que ejercen su actividad y tener en consideración las opiniones de los demás terceros interesados. A este respecto, las empresas deberán:

1. Contribuir al progreso económico, social y medioambiental con vistas a lograr un desarrollo sostenible.

2. Respetar los derechos humanos de las personas afectadas por sus actividades de conformidad con las obligaciones y compromisos internacionales del gobierno de acogida.

3. Estimular la generación de capacidades locales mediante una cooperación estrecha con la comunidad local, incluidos los sectores empresariales locales, desarrollando al mismo tiempo las actividades de la empresa en los mercados interiores y exteriores de una manera compatible con la necesidad de prácticas comerciales saludables.

4. Fomentar la formación del capital humano, particularmente mediante la creación de oportunidades de empleo y el ofrecimiento de formación a los empleados. 
5. Abstenerse de buscar o de aceptar exenciones no contempladas en el marco legal o reglamentario relacionadas con el medioambiente, la salud, la seguridad e higiene, el trabajo, la fiscalidad, los incentivos financieros $u$ otras cuestiones varias.

6. Apoyar y defender unos correctos principios de gobierno empresarial y desarrollar y aplicar unas buenas prácticas de gobierno empresarial.

7. Desarrollar y aplicar prácticas autodisciplinarias y sistemas de gestión eficaces que promuevan una relación de confianza recíproca entre las empresas y las sociedades en las que ejercen su actividad.

8. Promover el conocimiento por los empleados de las políticas empresariales y su conformidad con ellas, mediante una difusión adecuada de las mismas, incluso a través de programas de formación.

9. Abstenerse de tomar medidas discriminatorias o disciplinarias contra los trabajadores que elaboren, de buena fe, informes para la dirección o, en su caso, para las autoridades públicas competentes acerca de prácticas contrarias a la ley, a las Directrices o a las políticas de la empresa.

10. Alentar, cuando sea factible, a los socios empresariales, incluidos proveedores y subcontratistas, para que apliquen principios de conducta empresarial compatibles con las Directrices.

11. Abstenerse de cualquier injerencia indebida en actividades políticas locales.

Se anima a las empresas a comunicar informaciones adicionales que pueden incluir:

a) declaraciones de valores o declaraciones dirigidas al público en las que se expongan las normas de conducta, incluida información sobre las políticas sociales, éticas y medioambientales de la empresa y otros códigos de conducta que haya suscrito la empresa. Además, también podrán comunicarse la fecha de adopción, los países y las entidades en los que son aplicables dichas declaraciones y sus resultados en relación con las mismas;

b) información acerca de los sistemas de gestión de riesgos y de cumplimiento de las disposiciones legales y acerca de las declaraciones o códigos de conducta; 
c) información sobre las relaciones con los empleados y otros terceros interesados en la marcha de la empresa.

OCDE cuenta con 34 países miembros: Alemania, Australia, Austria, Bélgica, Canadá, Chile, Corea, Dinamarca, Eslovenia, España, Estados Unidos, Estonia, Finlandia, Francia, Grecia, Holanda, Hungría, Islandia, Irlanda, Israel, Italia, Japón, Luxemburgo, México, Noruega, Nueva Zelanda, Polonia, Portugal, Reino Unido, República Checa, República Eslovaca, Suecia, Suiza y Turquía. Varias empresas farmacéuticas multinacionales de estos países han adherido a las Directrices.

\section{World Business Council for Sustainable Development (WBCSD)}

EI WBCSD fue creado por industrial suizo Stephan Schmidheiny en 1992, también creador de Fundación Avina y de FUNDES. Tiene su sede en Ginebra (Suiza) y una oficina en Washington D.C. (Estados Unidos). Es una asociación global de unas 200 empresas que se ocupa exclusivamente de los negocios y el desarrollo sostenible. EI WBCSD proporciona una plataforma para que las compañías puedan explorar el desarrollo sostenible, compartir conocimiento, experiencias y mejores prácticas, y promover posiciones empresariales sobre estas cuestiones en una variedad de foros, en colaboración con gobiernos, organizaciones no gubernamentales y organizaciones intergubernamentales. Sus miembros provienen de más de 35 países y de 20 sectores industriales, con la participación de unos 1000 líderes de negocios a nivel mundial.

Son miembros de esta organización (ver www.wbcsd.org): Bayer, Novartis, Novo Nordisk, Novozymes y Roche.

Pacto Mundial de las Naciones Unidas (The Global Compact)

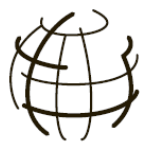
THE GLOBAL Fue anunciado en enero de 1999 con una iniciativa del secretario general de Naciones Unidas para que las empresas colaboraran para promover principios sociales y ambientales de carácter universal: "Optemos 
por el poder de los mercados con la autoridad de los ideales universales. Optemos por conciliar las fuerzas creativas del espíritu de la empresa privada con las necesidades de los desfavorecidos y las generaciones futuras". (Kofi Annan, secretario general de las Naciones Unidas. 1999).

El Pacto Mundial es una iniciativa voluntaria, en la cual las empresas se comprometen a alinear sus estrategias y operaciones con diez principios universalmente aceptados en cuatro áreas temáticas: derechos humanos, estándares laborales, medio ambiente y anti-corrupción. Las empresas deben:

\section{Derechos Humanos:}

1. Apoyar y respetar la protección de los derechos humanos proclamados a nivel internacional.

2. Asegurarse de que sus empresas no son cómplices de la vulneración de los derechos humanos.

\section{Estándares Laborales:}

3. Respetar la libertad de Asociación y el reconocimiento efectivo del derecho a la negociación colectiva.

4. Apoyar la eliminación de toda forma de trabajo forzoso o realizado bajo coacción.

5. Apoyar la erradicación del trabajo infantil.

6. Apoyar la abolición de las prácticas de discriminación en el empleo y ocupación.

\section{Medio Ambiente:}

7. Mantener un enfoque preventivo que favorezca el medio ambiente.

8. Fomentar las iniciativas que promuevan una mayor responsabilidad ambiental.

9. Favorecer el desarrollo y la difusión de las tecnologías respetuosas con el medio ambiente.

\section{Anticorrupción:}

10. Trabajar en contra de la corrupción en todas sus formas, incluidas la extorsión y el soborno.

Lanzado en 2000, el Pacto Mundial de Naciones Unidas es la iniciativa de ciudadanía corporativa más importante del mundo. A mayo de 2007, más de 3.000 empresas de 100 países, además de más de 700.000 
organizaciones sindicales y de la sociedad civil a nivel internacional, participan de la iniciativa. Todos trabajan para promover la ciudadanía corporativa responsable, asegurándose que el negocio sea parte de la solución para los desafíos de la globalización. De esta manera, el sector privado, en asociación con otros actores sociales, puede ayudar a lograr una economía mundial más sostenible e integradora.

Para participar en el Pacto Mundial, una empresa:

1. Envía una carta del CEO (avalada por el directorio) al Secretario General, expresándole su apoyo al Pacto Mundial y sus principios;

2. Implementa cambios en sus operaciones de manera que el Pacto Mundial y sus principios se conviertan en parte de la estrategia, cultura y operaciones del día a día;

3. Deberá promover públicamente el Pacto Mundial y sus principios a través de vehículos de comunicación tales como comunicados de noticias, discursos, etc.;

4. Deberá publicar en su memoria anual o informe corporativo similar (por ejemplo, informe de sostenibilidad) una descripción de las formas en las cuales está apoyando el Pacto Mundial y sus diez principios (es decir, una Comunicación del Progreso).

Laboratorios como Novartis, Sanofi-Aventis, Bayer, Novo Nordisk, Novozymes, Pfizer, Esteve y Serono están adheridos al Pacto Mundial.

\subsection{Informes sociales}

Global Reporting Initiative (GRI)

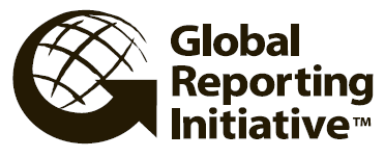

Un marco que aporta directrices sobre la elaboración y la comunicación de las memorias de RSE

La Global Reporting Initiative es una organización basada en redes que fue creada por CERES (Coalition Environmentally Responsible Economics), una red estadounidense de inversores, organizaciones ambientales y otros grupos de interés, con el Programa de las Naciones Unidas para el Medio Ambiente (PNUMA) como asociado. La GRI ha elaborado un marco que aporta directrices sobre la elaboración de memorias de RSE, incluyendo los 
impactos económicos, sociales y ambientales de una empresa. En el año 2000 se lanzó el primer marco (2000 Sustantibility Reporting Guidelines), que actualmente es la tercera versión de la GRI (G3). El desarrollo de las directrices es continuo y reúne diversos grupos de interés que, conjuntamente, evalúan y desarrollan el contenido del marco.

Tiene como misión mejorar la calidad, rigor y utilidad de los reportes corporativos de sustentabilidad (desempeño económico, ambiental y social), de forma tal que alcancen un nivel equivalente al de los reportes financieros. Está diseñado para el uso por parte de organizaciones de cualquier tamaño, sector o ubicación.

Más de 1.000 organizaciones de casi 60 países han declarado formalmente que usan las Directrices del GRI.

EI GRI recibe con agrado la participación de las empresas en la red del GRI, ya sea que recién la empresa se inicie en la elaboración de memorias o tenga amplia experiencia en el tema. Para comenzar a elaborar memorias se debe:

1. Obtener una copia de la Tercera Generación (G3) de los Informes de Sostenibilidad en el sitio web del GRI;

2. Utilizar los Principios para la Elaboración de Memorias para guiar la toma de decisiones sobre qué informar y cómo comunicarlo, luego use las Informaciones Estándar para preparar su memoria;

3. Registrar su memoria en línea y declare el nivel en el cual ha utilizado las guías de elaboración siguiendo los criterios de Nivel de Aplicación del GRI; $y$

4. Solicitar que el GRI analice el Nivel de Aplicación que ha declarado y agregue su memoria a su base de datos en línea.

Bristol-Myers Squibb Company fue la primera compañía farmacéutica en presentar su Memoria correspondiente al año 1999. Según el GRI Reports List las siguientes empresas del sector Healthcare Products han publicado su reporte en el año 2010: Abbott, Allergan, Apoteket, Baxter International, Bayer, Boticário, Coloplast Denmark, CSL, ESTEVE, Eumedics, F. Hoffmann-La Roche Ltd, Fosun Pharmaceutical, GlaxoSmithKline (GSK), Knecht\&Müller, LG Household and Health Care, Life Technologies, Medtronic, Millipore Corporation, Novartis International AG, Novo Nordisk, 
Novozymes, Orion Group, Pfizer Hungary, Roche Brazil, Sanofi-Aventis Group, Straumann, Takeda, Weleda Nederland N.V.

Debido al incremento en la adopción del Pacto Mundial y del GRI, el carácter complementario de las misiones y los marcos de trabajo de las organizaciones, ha generado como resultado una colaboración activa, y como respuesta GRI y Pacto Mundial produjeron el documento "Estableciendo la conexión" para brindar una guía práctica sobre cómo pueden usarse estos marcos globales en conjunto y con la mayor eficacia, con el fin de mejorar el valor y la facilidad de implementación de los Principios del Pacto Mundial y de comunicación de sus resultados.

\subsection{Acreditaciones y certificaciones}

AA1000 AccountAbility

Una serie de principios y normas para el aseguramiento y la participación de los grupos de interés

Norma surgida en 1999, por iniciativa del International Council of the Institute of Social and Ethical Accountability, con sede en el Reino Unido. Tiene por objetivo mejorar e incrementar la contabilidad social y ética, como también la realización de auditorías y reportes relacionados a ello. Incluye la creación de estándares de credibilidad de la organización, equivalentes a los principios generales de contabilidad y auditoría, a fin de establecer un proceso de verificación de responsabilidad.

Los principios de las normas AA1000 son tres, entre los cuales el principio de inclusividad es fundamental, e imprescindible para alcanzar los otros dos, de relevancia y de capacidad de respuesta.

El principio de inclusividad establece que una organización debe aceptar su responsabilidad sobre todos aquellos aspectos en los que genere un impacto y sobre aquellos que tengan un impacto sobre ella. La inclusividad se refiere a la participación de sus grupos de interés en el desarrollo y en el logro de una respuesta responsable y de una estrategia orientada hacia la sostenibilidad. En la práctica, esto implica identificar y comprender sus resultados e impacto social, ambiental y económico, y los puntos de vista 
de los grupos de interés, así como considerar y responder de manera coherente a las aspiraciones y necesidades de los grupos de interés respecto de las políticas y prácticas de la organización; y, finalmente, dar cuenta de sus decisiones, acciones e impactos sobre los grupos de interés.

El principio de relevancia consiste en determinar la relevancia e importancia de un asunto para la empresa y, también, para sus grupos de interés. Se considera un asunto relevante si es un tema que influirá en las decisiones, acciones y desempeño de una empresa o de sus grupos de interés.

El principio de la capacidad de respuesta es el modo en el cual la empresa responde a los asuntos de los grupos de interés que afectan a su desempeño en materia de sostenibilidad.

Los Principios de AccountAbility AA1000 se utilizan para orientar el aseguramiento de sostenibilidad de acuerdo con la AA1000AS (2008) y el compromiso con los grupos de interés de acuerdo con la AA1000SES (2005). La norma de aseguramiento AA1000AS es un estándar de aplicación general para evaluar, atestiguar y fortalecer la credibilidad y calidad del informe de sostenibilidad de una organización y de sus principales procesos, sistemas y competencias. Asimismo, aporta orientación sobre los elementos clave del proceso de aseguramiento.

Laboratorios como Astra Zeneca, Novo Nordisk y Novozymes adoptaron o hicieron referencia a las normas AA1000 en sus reportes de RSE o de sustantibilidad (ver http://www.theaccountabilityproject.ca/aa1000.html).

\section{Social Accountability 8000 (SA 8000)}

\section{Una norma certificable enfocada en las condiciones de trabajo}

Esta norma fue desarrollada en 1997 por Social Accountability International (SAI), organismo no gubernamental con sede en Nueva York, una organización creada por varios grupos de interés que comparten el objetivo de mejorarel ejercicio de los derechos humanos de los trabajadores en todo el mundo. SA 8000 fue creada para ofrecer una clarificación frente a la multitud de estándares que habían sido desarrollados para controlar las condiciones de trabajo en las cadenas de 
suministro. El objetivo era ofrecer una norma basada en acuerdos internacionales, por lo cual SA 8000 se apoya en las convenciones de la Organización Internacional de Trabajo y en los acuerdos de las Naciones Unidas.

La norma se orienta hacia los impactos sociales de la empresa, y se ocupa principalmente del trabajo infantil, el trabajo forzoso y obligatorio, la seguridad y la salud en el trabajo, los derechos de sindicación y de negociación colectiva, la discriminación, las medidas disciplinarias, el horario de trabajo, la remuneración y los sistemas de gestión. La norma establece criterios específicos para cada asunto y también define claramente todos los conceptos que utiliza.

La norma es una de las pocas que es certificable, aunque sólo certifica a nivel de instalaciones y no toda la empresa. La iniciativa establece diferencias en sus exigencias para con las instalaciones de producción de menos capacidad, tales como menos días de auditorías y sistemas de gestión menos elaborados.

La verificación de SA 8000 ha sido elaborada de modo que sea compatible con los sistemas de gestión de la Organización Internacional de Estándares (International Organization for Standardization, ISO) y el International Forest Stewardship Council (FSC). SA ha desarrollado una agencia de acreditación (Social Accountability Accreditation Services) que proporciona esos servicios. La certificación es válida por tres años y cada seis meses se realiza una auditoría de verificación, que exige requisitos de procedimiento mínimos, entrevistas con empleados y un sistema de reclamaciones. En efecto, SA 8000 proporciona medios a los grupos de interés para que puedan reclamar si la empresa no cumple con los requisitos de la norma.

La norma es aplicable globalmente, independientemente de la ubicación o el sector industrial. Sin embargo, por su enfoque hacia las condiciones de trabajo, el uso de la norma es común en industrias conocidas por tener malas condiciones laborales, y también en países con ese tipo de problemas, tales como India y China.

GlaxoSmithKline, Bioiberica y otras compañías farmacéuticas extranjeras han certificado SA 8000. 


\section{Norma SGE 21}

\section{Norma de GESR certificable}

La Norma SGE 21 promueve un sistema de gestión ética y socialmente responsable. Esta norma fue desarrollada por la organización Forética en el año 1999. Forética es una asociación sin ánimo de lucro cuya iniciativa surge en el seno del X Congreso de Empresas de Calidad, de Barcelona, en el año 1999, donde un nutrido grupo de directivos y líderes de opinión se cuestionan de qué manera pueden poner en valor una cultura de empresa basada en la responsabilidad de todos sus miembros frente al conjunto de la sociedad y el entorno.

De esta manera, un amplio número de profesionales, empresas, académicos y ONG crearon un foro multidisciplinar, donde todos sus socios colaboran en el fomento de una gestión responsable.

Uno de sus primeros frutos fue la elaboración de la Norma de Empresa SGE 21, en la que participaron más de cien expertos representando a todos los grupos de interés. Este documento soporta el primer Sistema de Gestión Ética y Socialmente Responsable europeo. Este estándar permite una gestión eficiente de la responsabilidad social, proporcionando además una metodología aplicable para la evaluación e incluso verificación del sistema por tercera parte (certificación).

La edición 2008 de la Norma SGE 21 es la tercera revisión desde su primer lanzamiento en octubre del año 2000. El sistema que propone parte de modelos consolidados como los de calidad y medioambiente, a los que enriquece a través de una visión multistakeholder. La Norma SGE 21 tiene como referencia las normativas internacionales de las más reputadas instituciones, públicas o privadas (Varias de las que ya se mencionaron en este punto).

La SGE 21 fue diseñada de forma que permitiese adaptarse a las necesidades de cada empresa. Pueden señalarse como puntos fuertes de la norma las siguientes características:

1. Flexibilidad. Puede adaptarse a todo tipo de empresa, en cualquier sector de actividad. La norma no entra en los contenidos de los documentos o de las políticas, sino que se limita a verificar su existencia y 
su cumplimiento. Hay unos requisitos mínimos en las diversas áreas que analiza, pero a partir de ahí se deja a discreción de cada empresa determinar qué acciones o políticas van a incluirse en el sistema de gestión y qué indicadores se definirán para medir su implantación.

2. Escalabilidad. La norma puede ser implantada en toda la organización o bien pueden definirse niveles de implantación (por áreas de gestión, centros de trabajo o cualquier otro parámetro que permita auditar por etapas la empresa).

Se contempla que el proceso de certificación pueda abarcar un ciclo de tres años, de modo que al final de los tres años se haya auditado la totalidad de la empresa y se hayan propuesto planes de mejora para sucesivos años.

3. Compatibilidad. Al participar del enfoque de los sistemas de gestión de calidad la norma es compatible con otras normas, como la ISO $9000 / 2000$ o la ISO 14000, de modo que en aquellos apartados de la norma que se refieren a aspectos auditados por otras normas, aquellas empresas que hayan sido certificadas a través de esas normas no necesitan volver a ser auditadas por la SGE 21, permitiéndose así un cierto ahorro de tiempo y dinero.

4. Información. El proceso de certificación conlleva que se genere un gran volumen de información y que se gestione de forma sistemática, lo que facilita su posterior utilización para otras tareas de comunicación, como puede ser la elaboración de memorias. La SGE 21 divide la organización en 9 áreas de gestión (requisitos) y en cada una de ellas de determinan los valores auditables así como los indicadores para concretar la evidencia de su implantación:

- Alta Dirección

- Clientes

- Proveedores

- Personas que integran la organización

- Entorno social

- Entorno ambiental

- Inversores

- Competencia 
- Administraciones públicas

La norma contempla al menos tres elementos básicos en el sistema de gestión. En primer lugar, una declaración de principios, a través de la cual la dirección haga público su compromiso con los valores de la organización y que sea conocida por todos los empleados. En segundo lugar, un código de conducta que concrete estos valores en pautas de actuación aplicables a toda la organización. Por último, un comité encargado de atender cualquier incidencia en la aplicación de las políticas de responsabilidad social y otros conflictos de carácter ético, y que es el máximo responsable del diálogo con las partes interesadas.

A la hora de diseñar la norma se ha prestado un especial cuidado en asegurar la seriedad de la auditoría, de modo que hay hasta tres diferentes momentos de evaluación antes de proceder a la certificación. Cuando una empresa solicita ser certificada se procede a un primer estudio de la documentación para analizar si la empresa es susceptible de ser certificada o qué condiciones deberían darse para iniciar la certificación. Si se determina la viabilidad, se procede a una auditoría externa, por parte de una entidad reconocida por Forética, que emite un informe de auditoría. Por último, este informe es revisado por un Comité de Certificación designado por la Dirección Técnica de Forética y compuesto por la entidad certificadora que ha redactado el informe, otra certificadora, una ONG, un socio de Forética experto en responsabilidad social, el Presidente de Forética y un miembro del área técnica de Forética. Este Comité a la vista del informe puede denegar la certificación, puede detectar desviaciones menores que deberán ser sujeto de planes de mejora o puede conceder la certificación de Gestión Etica y Responsabilidad Social. Este certificado es revisado anualmente con auditorías de seguimiento y cada tres años con auditorías completas.

Forética, además de haber diseñado la norma y revisarla de forma continuada, se encarga también de formar al personal de las entidades certificadoras así como a los auditores internos de las empresas certificadas, y de solucionar posibles conflictos que surjan en la interpretación de la norma o en el proceso de certificación. 
En Argentina existe una filial de Forética de España, siendo la primera sede de la institución a nivel internacional. Forética Argentina nace en el 2006 con el propósito de convocar a empresas comprometidas con la gestión socialmente responsable y guiarlas en el desarrollo de políticas verificables de RSE.

En España, forman parte de Forética los laboratorios AstraZeneca, Merck Sharp \& Dohme, Novartis y Sanofi-Aventis.

\section{OHSAS 18001:2007}

\section{Norma de Gestión de la Seguridad y Salud \\ en el Trabajo certificable.}

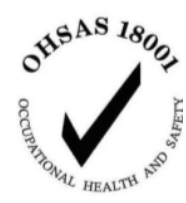

La norma OHSAS está basada en la norma británica original British Standard - BS 8800. Participaron en su desarrollo las principales organizaciones certificadoras del mundo, abarcando más de 15 países de Europa, Asia y América.

Los tres documentos que componen la OHSAS 18000 son una serie de estándares voluntarios internacionales relacionados con la gestión de seguridad y salud ocupacional.

Esta norma se aplica para establecer un sistema de prevención de riesgos laborales; eliminar o reducir al máximo los riesgos del personal y de otras partes interesadas que puedan estar expuestas a riesgos para su salud y seguridad en el trabajo relacionados con las actividades llevadas a cabo por la organización; para implementar, actualizar y mejorar de manera continua un sistema de prevención de riesgos laborales; $y$, entre otros aspectos más, para asegurar la conformidad con su política de salud y seguridad en el trabajo.

La OHSAS 18001 exige específicamente documentar:

- La política (deben indicarse explícitamente los compromisos sobre mejora continua y de cumplimiento, como mínimo, de la legislación y otros requisitos que la empresa suscriba).

- Los resultados de las evaluaciones de riesgos y los efectos de los controles de los riesgos.

- Los objetivos de seguridad y salud. 
- Las responsabilidades y autoridad.

- Los recursos y plazos para alcanzar los objetivos.

- Los acuerdos sobre participación y consulta.

- La revisión por la dirección

Novatis, AstraZeneca, Pfizer tienen la certificación.

\section{ISO 14001}

\section{Norma de Gestión Medioambiental certificable}

La ISO 14001 forma parte de una serie de normas internacionales de gestión ambiental aplicables a cualquier organización. Basada en el ciclo Planificar - Hacer - Verificar - Actuar, la ISO 14001:2004 especifica los requisitos para un sistema de gestión medioambiental que le permiten a una organización desarrollar e implementar una política y objetivos que tengan en cuenta los requisitos legales y otros requisitos a los que la organización suscriba, y brindar información sobre los aspectos ambientales significativos. Aplica a aquellos aspectos medioambientales que la organización identifica, como también a los que puede controlar y puede influir. No establece criterios específicos de desempeño ambiental.

ISO 14001:2004 es certificable por una organización externa. Novartis, AstraZeneca, Pfizer tienen la certificación.

\section{EMAS}

\section{Sistema de Gestión y Auditoría Medioambiental}

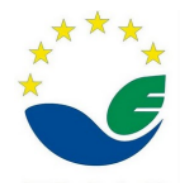

El Sistema comunitario de gestión y auditoría medioambientales (EMAS) permite la participación con carácter voluntario de organizaciones de dentro y fuera de la Comunidad Europea. El programa ha estado abierto a la participación de las empresas desde 1995 e inicialmente se limitó a las empresas del sector industrial. Desde 2001 EMAS está abierto a todos los sectores económicos incluyendo los servicios públicos y privados. En 2009 se revisó y modificó el Reglamento de EMAS por segunda vez y entró en vigencia el 11 de enero de 2010. 
El objetivo de EMAS, como instrumento importante del Plan de acción sobre consumo y producción sostenibles y una política industrial sostenible, consiste en promover mejoras continuas del comportamiento medioambiental de las organizaciones mediante el establecimiento y la aplicación por su parte de sistemas de gestión medioambiental, la evaluación sistemática, objetiva y periódica del funcionamiento de tales sistemas, la difusión de información sobre comportamiento medioambiental, el diálogo abierto con el público y otras partes interesadas, y la implicación activa del personal en las organizaciones, así como una formación adecuada.

El Reglamento (CE) № 765/2008 establece organismos de acreditación nacionales que son los responsables de la acreditación y supervisión de los verificadores medioambientales, quienes validan la declaración medioambiental que presenta la organización para obtener la inscripción en el registro.

Filiales europeas de laboratorios como Abbott, Novartis, Pfizer están registrados.

\subsection{Principales programas $y$ acciones en materia de $R S E$ de las empresas estudiadas}

\section{Bagó}

www.bago.com.ar

Se orienta en salud, ciencia, cultura y educación. Con "Cuidado de la salud" dona medicamentos destinados a cubrir necesidades terapéuticas específicas de sectores carenciados de la población, y a través de instituciones sin fines de lucro como Tren Hospital Alma, Fundación N. D. Flexer, Casa Manu y Cascos Blancos. Trabaja con comunidades aborígenes y hospitales de frontera, y se da prioridad en la evaluación de proyectos de la Fundación del Hospital Fernández para cubrir las necesidades de aparatología y equipamiento. En lo cultural, edita anualmente un libro que se distribuye gratuitamente a organizaciones científicas y educativas; apoya a ciclos de arte como "A todo arte" y conciertos de música sinfónica. Promueve encuentros culturales y 
conferencias abiertas a la comunidad como las "Charlas del museo". El programa "Educación" beca a estudiantes de facultades de Medicina, Bioquímica y Farmacia para completar sus estudios y se los estimula con la Medalla de Oro Bagó al mejor promedio. Realiza "Visitas a plantas" para estudiantes y profesionales del área de la salud para complementar su formación académica.

\section{Bayer}

www.bayer.com.ar

Posee un programa integral en la región Cono Sur, liderado desde la Argentina ("Bayer Emprende"). Se centra en educación, salud, cambio climático y voluntariado corporativo. "UNES, Utilicemos Nuestro Espíritu Solidario" unifica las iniciativas de voluntariado corporativo. Ayudó a más de 70 instituciones y más de $30 \%$ de los empleados participó del programa en alguna ocasión. En medio ambiente, lanzó un programa de concientización para niños y jóvenes sobre qué medidas adoptar para reducir "Tu huella climática". La plataforma base de este programa es tuhuellaclimatica.com donde se da información y consejos, y se promocionan cuatro concursos para niños y jóvenes, con importantes premios.

\section{Novartis}

www.novartis.com.ar

Mediante el "Programas para pacientes" brinda medicamentos gratuitos y ofrece apoyo a quienes carecen de seguro médico o no pueden asumir el costo de los tratamientos para lepra, tuberculosis, malaria y algunas enfermedades oncológicas. El "Programa Novartis comunidad", junto con la Fundación Tzedaká y Cáritas Buenos Aires, implementa la donación de medicamentos a pacientes de escasos recursos. Como respuesta a una necesidad prioritaria de salud pública, la pandemia mundial de gripe $A$ (H1N1), cerca de 300 empleados de Novartis de diferentes divisiones se ofrecieron como voluntarios para realizar funciones temporales en la División Vacunas y Diagnósticos para apoyar la producción de las vacunas pandémicas contra la gripe. Cuenta con una Política Global de Diversidad e 
Inclusión; organizó una campaña interna de vacunación, gratuita y voluntaria para los empleados y sus familias, y les brinda asesoramiento gratuito en temas legales, financieros y psicológicos. Implementa el "Día Mundial de Novartis de trabajo para la comunidad". En medio ambiente mejora la eficiencia energética y reduce las emisiones de dióxido de carbono. Lleva a cabo programas de reciclado. Cuenta con Código de Conducta y organiza cursos de capacitación sobre temas de integridad y talleres de RSE. Firmó y ha sido miembro de grupo promotor que lanzó el Pacto Mundial en la Argentina en 2004. Integra la red de Empresas contra el Trabajo Infantil, promovida por el Ministerio de Trabajo.

\section{Roche Argentina}

www.roche.com.ar

En el marco de la actividad global Children's Walk renovó el padrinazgo de una habitación en la Casa Garrahan y participa del programa de reciclado. Apoya Actividades de Fundación Nuevos Caminos. Colabora con el programa de becas "Tigre educa" impulsado desde el Municipio de Tigre, junto a Conciencia. En Hermoso Campo (Chaco) por Red Solidaria, acompaña un proyecto de huertas comunitarias -elaborado por el municipio y el INTA. Colabora reuniendo alimentos entre empleados para el comedor Confiar, de Pilar. Se vincula con distintas organizaciones para brindar a los pacientes información y colaborar con campañas de detección precoz y prevención de enfermedades. Implementa Green IT, para promover el uso responsable y correcto reciclado de la tecnología. Vende equipos informáticos usados en buen estado a sus empleados, para generar fondos para acciones de RSE.

Muchos empleados de Roche participan como trabajadores voluntarios en sus propias comunidades, contribuyendo con sus valores, tiempo y energía para programas sociales, instituciones de salud y escuelas. Roche apoya ese vínculo siempre que sea posible. El voluntariado de los empleados en considerado como un motor de cambios positivos, pero Roche deliberadamente evita ejercer cualquier influencia sobre el tipo o volumen de trabajo voluntario de los empleados. 
En todo el Grupo Roche existen situaciones en las cuales el trabajo comunitario de los empleados es favorecido por horarios de trabajo flexibles en la empresa y licencias otorgadas para ese fin. Cuando consideramos los posibles beneficiarios de donaciones, damos preferencia a los proyectos $u$ organizaciones en donde los empleados de Roche están involucrados.

\section{Roemmers}

www.roemmers.com.ar

Desarrolla, desde 1992, una acción de alcance nacional con los residentes. Es una de las tareas que manifiestan su firme voluntad de acompañar y apoyar la tarea del médico residente, consciente de los objetivos rectores en las residencias médicas y de la ardua labor que desarrollan en el área asistencial y de capacitación científica. Así Roemmers les obsequia un libro de su especialidad, a elección.

La Fundación Alberto J. Roemmers, creada en 1975 en memoria de Don Alberto J. Roemmers, nació con el fin de promover el desarrollo de las ciencias de la salud en todos sus niveles. Más de 300 proyectos de investigación, divididos en tres categorías (investigadores nóveles, de formación intermedia y formados) son presentados anualmente a la Fundación. Hasta el presente, la institución ha adjudicado subsidios para cerca de 1000 proyectos de investigación.

En el área de la docencia, la Fundación lleva a cabo jornadas, simposios y seminarios - teóricos y prácticos - que permiten establecer un contacto directo entre los médicos argentinos y sus colegas del exterior.

En el campo de la enseñanza, la Fundación dicta cursos de enfermería en la ciudad de Buenos Aires y en el interior del territorio argentino.

Asimismo, edita libros con las actas de los simposios, jornadas y conferencias es otro aspecto del quehacer de la institución. Sus volúmenes se distribuyen gratuitamente a los concurrentes y a instituciones médicas de todo el país. Por otro lado, la institución coedita libros de texto de medicina, así como los catálogos de las publicaciones científicas de la Academia Nacional de Medicina, de la Asociación Médica Argentina y de la Facultad de Medicina de Buenos Aires. 
Fundamentos y pautas para una Gestión Ética y Socialmente Responsable (GESR)

Aplicación en empresas del sector farmacéutico

\subsection{Cuestionario dirigido a los responsables de RSE}

Bloque 1 - Información general sobre su empresa

\begin{tabular}{|l|l|}
\hline Empresa & \\
\hline Origen de la empresa (nacional o extranjero) & \\
\hline Número aproximado de empleados & \\
\hline $\begin{array}{l}\text { Describir brevemente la naturaleza de los } \\
\text { procesos realizados por la empresa como un } \\
\text { todo }\end{array}$ & \\
\hline
\end{tabular}

\section{ORGANIZACIÓN DE "RSE"}

P.1. En su empresa, ¿la gestión de RSE está a cargo de un responsable?

1. SI

2. NO

3. NS/NC

$\begin{array}{lll}\text { 1. SI } & \text { 2. NO } 3 . N S / N C\end{array}$

P.2 ¿Tiene su empresa un departamento o área de RSE?

P.3 ¿De quién depende el responsable de RSE?

1. Del Directorio

2. De la Gerencia General

3. Del área de Relaciones Institucionales

4. Del área de Recursos Humanos

5. De otra área (especificar) 


\section{Bloque 2 - Sistema de Gestión Ética y Socialmente Responsable (GESR).}

P. 4. ¿Su empresa aplica formalmente o tiene en estudio alguno de estos sistemas de gestión económica, social y ambientalmente responsable como iniciativas de RSE?

1. Directrices de la OCDE

2. Principios del Pacto Global

3. ISO 14001/EMAS (Esquema Europeo de Auditoría y Gestión Ambiental)

4. SGE 21

5. AA 1000

6. OSHAS 18001

7. SA 8000

8. Indicadores GRI

9. Otro (indicar)

P. 5. En caso que la respuesta anterior sea negativa: ¿existen restricciones o limitantes que impiden o que obstruyen la aplicación de estos sistemas?

P.6. Identifique 5 grupos de interés (stakeholders) prioritarios en relación con la gestión responsable de su empresa.

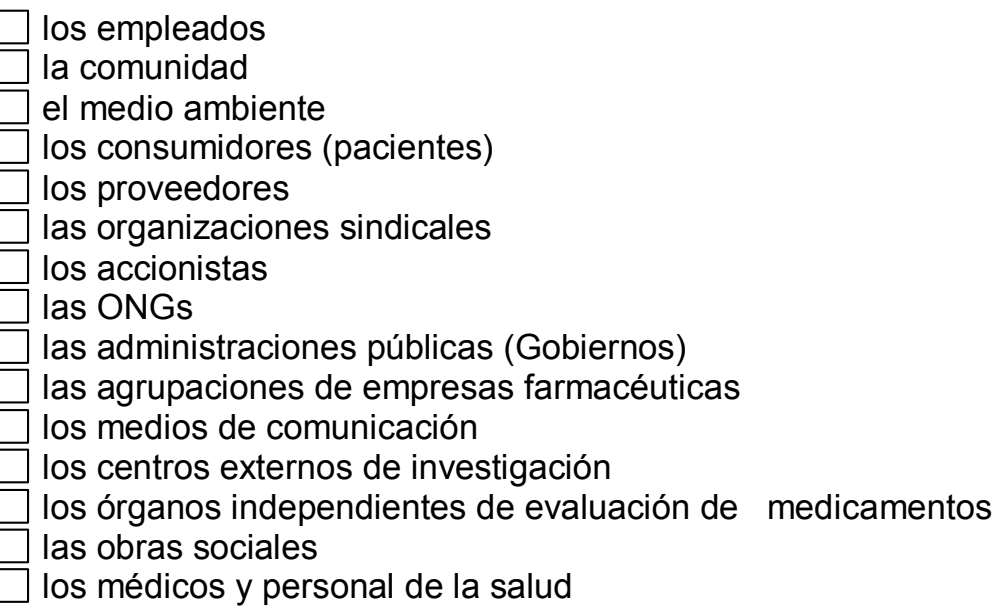


P (7 a 18) ¿Cuál es el grado de desarrollo de la gestión responsable de su empresa con relación a los siguientes temas de RSE?

\begin{tabular}{|c|c|c|c|c|c|}
\hline Temas de RSE & Muy bajo & Bajo & Medio & Alto & Muy Alto \\
\hline $\begin{array}{l}\text { 7. Valores y principios éticos claramente definidos y } \\
\text { comunicados }\end{array}$ & $\square 1$ & $\square 2$ & $\square 3$ & $\square 4$ & $\square 5$ \\
\hline $\begin{array}{l}\text { 8. Auditorías periódicas para garantizar el pleno } \\
\text { cumplimiento de las normas de la empresa y } \\
\text { requisitos legales que afectan a su actividad, } \\
\text { incluyendo la legislación y normativa que sea } \\
\text { específica de su sector, entorno local, ambiental, } \\
\text { social y laboral allí donde opere }\end{array}$ & $\square 1$ & $\square 2$ & $\square 3$ & $\square 4$ & $\square 5$ \\
\hline $\begin{array}{l}\text { 9. Política sobre la prevención de sobornos, } \\
\text { corrupción y mecanismos para garantizar que se } \\
\text { cumple (como capacitación, seguimiento y } \\
\text { controles) }\end{array}$ & $\square 1$ & $\square 2$ & $\square 3$ & $\square 4$ & $\square 5$ \\
\hline $\begin{array}{l}\text { 10. Desarrollo de mecanismos y herramientas de } \\
\text { comunicación y reporting }\end{array}$ & $\square 1$ & $\square 2$ & $\square 3$ & $\square 4$ & $\square 5$ \\
\hline $\begin{array}{l}\text { 11. Política de calidad claramente definida y } \\
\text { comunicada, asumiendo plenamente el } \\
\text { compromiso ético que supone la producción y } \\
\text { comercialización de medicamentos de uso } \\
\text { humano. }\end{array}$ & $\square 1$ & $\square 2$ & $\square 3$ & $\square 4$ & $\square 5$ \\
\hline $\begin{array}{l}\text { 12. Desarrollo de buenas prácticas a lo largo de } \\
\text { todo el proceso de relación con el consumidor. }\end{array}$ & $\square 1$ & $\square 2$ & $\square 3$ & $\square 4$ & $\square 5$ \\
\hline $\begin{array}{l}\text { 13. Influencia dentro de la cadena de suministro } \\
\text { para impulsar los estándares de comportamiento } \\
\text { ético. }\end{array}$ & $\square 1$ & $\square 2$ & $\square 3$ & $\square 4$ & $\square 5$ \\
\hline $\begin{array}{l}\text { 14. Política claramente definida y comunicada que } \\
\text { condenan la discriminación sobre la base de } \\
\text { raza, color, edad, género, orientación sexual, } \\
\text { etnia, religión, afiliación política, afiliación sindical } \\
\text { o de estado civil }\end{array}$ & $\square 1$ & $\square 2$ & $\square 3$ & $\square 4$ & $\square 5$ \\
\hline $\begin{array}{l}\text { 15. Política claramente definida y comunicada } \\
\text { sobre el trabajo infantil según como se define por } \\
\text { las leyes de los países en los que la compañía } \\
\text { opera }\end{array}$ & $\square 1$ & $\square 2$ & $\square 3$ & $\square 4$ & $\square 5$ \\
\hline $\begin{array}{l}\text { 16. Sistema de evaluación y mejora continua en } \\
\text { salud, seguridad y bienestar en el trabajo (en las } \\
\text { operaciones de la empresa, a lo largo de toda la } \\
\text { cadena de suministro, en las comunidades } \\
\text { donde opera) }\end{array}$ & $\square 1$ & $\square 2$ & $\square 3$ & $\square 4$ & $\square 5$ \\
\hline $\begin{array}{l}\text { 17. Establecimiento de acciones con repercusión } \\
\text { positiva en la comunidad }\end{array}$ & $\square 1$ & $\square 2$ & $\square 3$ & $\square 4$ & $\square 5$ \\
\hline $\begin{array}{l}\text { 18. Sistema de gestión que le permite desarrollar e } \\
\text { implementar una política y objetivos que tengan } \\
\text { en cuenta los requisitos legales y otros } \\
\text { requisitos a los que la organización suscribe } \\
\text { sobre medioambiente y cambio climático }\end{array}$ & $\square 1$ & $\square 2$ & $\square 3$ & $\square 4$ & $\square 5$ \\
\hline
\end{tabular}


Fundamentos y pautas para una Gestión Ética y Socialmente Responsable (GESR)

Aplicación en empresas del sector farmacéutico

\begin{tabular}{|c|c|c|c|c|}
\hline $\begin{array}{l}\mathrm{P}(19 \text { a } 27) \text { ¿Existen acciones } \\
\text { concretas de RSE asociadas a las } \\
\text { siguientes áreas en su empresa? }\end{array}$ & $\begin{array}{l}\text { 1. } \mathrm{Si} \text {, } \\
\text { existen }\end{array}$ & $\begin{array}{l}\text { 2. No existen, } \\
\text { pero está } \\
\text { previsto } \\
\text { implementarlas } \\
\text { en los } 12 \\
\text { próximos } \\
\text { meses } \\
\end{array}$ & $\begin{array}{l}\text { 3. No existen, } \\
\text { pero está } \\
\text { previsto } \\
\text { implementarlas } \\
\text { a más largo } \\
\text { plazo }\end{array}$ & $\begin{array}{l}\text { 4. No existen, } \\
\text { ni tenemos } \\
\text { previsto } \\
\text { implementarlas }\end{array}$ \\
\hline 19. Unidades estratégicas de Negocios & $\square$ & $\square$ & $\square$ & $\square$ \\
\hline 20. Recursos Humanos & $\square$ & $\square$ & $\square$ & $\square$ \\
\hline 21. Comercialización o marketing & $\square$ & $\square$ & $\square$ & $\square$ \\
\hline 22. Finanzas & $\square$ & $\square$ & $\square$ & $\square$ \\
\hline 23. Compras & $\square$ & $\square$ & $\square$ & $\square$ \\
\hline 24. Producción & $\square$ & $\square$ & $\square$ & $\square$ \\
\hline 25. Sistemas para Información y Control & $\square$ & $\square$ & $\square$ & $\square$ \\
\hline 26. Auditoría Interna & $\square$ & $\square$ & $\square$ & $\square$ \\
\hline 27. NS/NC & $\square$ & $\square$ & $\square$ & $\square$ \\
\hline
\end{tabular}

P.28 ¿Las políticas de RSE responden a políticas globales/regionales o son específicas al país?

\begin{tabular}{|c|c|}
\hline $\begin{array}{l}\text { P. } 29 \text { ¿Cuenta su empresa con presupuesto } \\
\text { asignado a acciones de RSE? } \\
\square \\
\square \text { 1. Si } \\
\text { 2. No } \\
\text { 3. NS/NC }\end{array}$ & 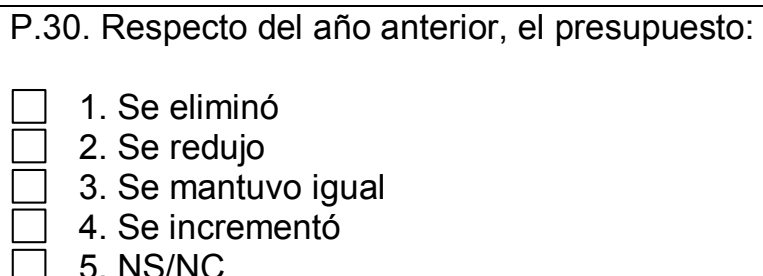 \\
\hline
\end{tabular}

\begin{tabular}{|l|l|}
\hline Nombre & \\
\hline Departamento/Gerencia & \\
\hline Número de teléfono de contacto & \\
\hline Fecha & \\
\hline
\end{tabular}

